\title{
伴随冬季北太平洋副热带海洋锋强度变化的大气 扰动异常及对中纬度大气平均场的影响
}

\author{
王丽颖 (1), 胡海波 ${ }^{(1)}$ (2) 杨修群 (1), 任雪娟 ${ }^{(1)}$ \\ (1) 中国气象局-南京大学气候预测研究联合实验室, 南京大学大气科学学院, 南京 210093; \\ (2) 气象灾害教育部重点实验室, 南京信息工程大学, 南京 210044 \\ *通讯作者, E-mail: huhaibo@nju.edu.cn
}

收稿日期: 2016-02-03; 接受日期: 2016-04-29; 网络版发表日期: 2016-09-22

国家自然科学基金项目(批准号: 41330420, 41275068)、国家重大基础研究计划项目(编号: 2012CB956002, 2016YFA0600303)、江苏省科技 厅面上项目(编号: SBK2015020577)和气象灾害教育部重点实验室(南京信息工程大学)开放课题项目(编号: KLME1501)资助

\begin{abstract}
摘要中纬度海洋热力状况异常影响大气主要通过两种途径: 非绝热加热的直接强迫作用和大气瞬变涡旋 反馈的间接强迫作用，而后者的作用并没有被很好地认识. 为了进一步理解间接强迫作用的物理机制，本文利 用观测资料分析和区域大气模式模拟, 研究了伴随冬季北太平洋副热带海洋锋强度变化的中纬度大气场异常, 特别是对流层中高层不同频率的涡旋扰动活动的异常. 实际观测和数值试验结果均表明, 当北太平洋副热带海 表面温度锋偏强时, 其上空的中纬度大气经向温度梯度增强; 对应此时的大气斜压性增强, 且中纬度大气西风 急流整层加速; 然而增强的大气斜压性并不对应一致性增强的大气涡旋扰动活动. 中纬度大气的涡旋扰动根 据其生命周期, 进一步划分为高频(2 7 天)和低频(10 90天)浴旋扰动. 研究结果表明偏强的北太平洋副热带海 洋锋对应着增强的中纬度大气高频涡旋扰动和减弱的低频涡旋扰动; 其中, 中纬度大气高频扰动活动的增强, 将有利于削弱中纬度大气经向温度梯度, 从而减弱中纬度大气斜压性; 而高频扰动对纬向风倾向项的正贡献, 有利于中纬度急流中心北侧及下游区域的西风加速, 形成中纬度西风相当正压结构的增强; 大气低频扰动的 减弱, 对中纬度大气纬向风倾向项产生负贡献, 不利于急流的纬向均匀化, 而其热力强迫异常则有利于维持中 纬度对流层中层大气的经向温度梯度。
\end{abstract}

关键词北太平洋副热带锋, 强度变化, 天气尺度瞬变扰动, 低频瞬变扰动, 中纬度海气相互作用

\section{1 引言}

冬季北太平洋海盆, 至少存在两条主要的纬向延 伸的海表面温度(SST)经向梯度带状大值区. 其中偏 南的一条位于 $28^{\circ} \mathrm{N} 32^{\circ} \mathrm{N}$ 附近, 跨越整个北太平洋海
盆, 被记为北太平洋副热带海洋锋区(STFZ)(Nakamura 等, 1997; Nakamura 和 Kazmin, 2003). 副热带锋与北 太平洋副热带逆流相依并存, 位于太平洋中部西风 带和信风带的切变区, 与海面风场变化关系密切(Uda 等, 1969; Roden, 1975, 1980; 管秉贤, 1987; Kobashi等,

中文引用格式: 王丽颖, 胡海波, 杨修群, 任雪娟. 2016. 伴随冬季北太平洋副热带海洋锋强度变化的大气扰动异常及对中纬度大气平均场的影响. 中国科 学: 地球科学, 46: 1658-1674, doi: 10.1360/N072015-00497

英文引用格式: Wang L Y, Hu H B, Yang X Q, Ren X J. 2016. Atmospheric eddy anomalies associated with the wintertime North Pacific subtropical front strength and their influences on the seasonal-mean atmosphere. Science China Earth Sciences, 59: 2022-2036, doi: 10.1007/s11430-016-5331-7 
2008). 另一条海表面经向温度梯度大值带位于 $42^{\circ} \mathrm{N}$ 附 近且纬向延伸, 记为北太平洋副极地海洋锋区(SAFZ). 副极地海洋锋由来自亲潮的冷水和来自黑潮的暖水 交汇形成, 结构复杂, 且温度梯度的强度比副热带海 洋锋更强(Roden, 1980; Yuan和 Talley, 1996; Nakamura 等, 1997; Nakamura 和 Kazmin, 2003; Yasuda, 2003).

最近的研究表明, 海洋锋区是中纬度海洋影响上 空大气的显著区域(Small等, 2008; Kelly等, 2010; Kwon 等, 2010). 在大气边界层内, 海洋锋至少可以通过两种 机制影响上空大气, 造成大气边界层层结结构和近表 面风速在海洋锋区南、北两侧的显著差异(Xie, 2004; 徐海明等, 2008; 徐蜜蜜等, 2010; Tanimoto等, 2011; 谢 傲等, 2014). 一种为Wallace等(1989)和Hayes等(1989) 提出的近表面动量垂直混合机制: 海洋锋区低纬侧的 暖海温降低大气边界层稳定度, 增强垂直混合从而增 加海表面风速; 而在海洋锋高纬侧的冷海温区, 垂直 混合受到抑制, 海表面风速减小. 另一种为Lindzen和

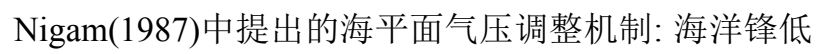
纬侧的暖海温使得空气增暖, 海平面气压降低, 而在 海洋锋冷海温一侧空气变冷, 海平面气压升高, 这样 越海洋锋区的海平面气压梯度会驱动空气由冷水向 暖水区加速. 在海洋锋影响边界层大气的过程中, 这 两种机制可能都起作用, 但在不同的海域其相对贡献 不同 (Xu等, 2010). 近期的研究也指出, 海洋锋对上空 大气的影响不仅局限于大气的边界层区域, 它能引起 整个对流层大气的调整(Kobashi等, 2008; Minobe等, 2008; Tokinaga等, 2009; Xu等, 2011). 海洋锋上空的海 表面风场辐合可以产生深厚的上升运动并一直延伸 到对流层高层, 对局地的云和降水都有显著影响.

在北太平洋海域内, 由于副极地锋的经向温度 梯度较强, 关于其强度和位置变化对中纬度大气环 流场的影响已有很多的研究(Nakamura等, 1997, 2008; Nakmamura和Kazmin, 2003; Kelly等, 2010; Taguchi等, 2012). 其中, Nakamura和 Kazmin(2003)指出冬季北太 平洋副极地锋有明显的年代际变化. 在 20 世纪 80 年代 中期, 北太平洋海温偏冷时, 副极地锋经向较宽, 强度 较弱且位置偏南; 而在 20 世纪 90 年代初期北太平洋海 温偏暖时, 副极地锋较窄, 强度偏强且位置偏北. 副极 地锋的经向位移主要是由海盆尺度风场变化引起的海 洋动力调整所致(Nonaka等, 2008), 且会引起冬季大气 类似太平洋北美型(PNA)的相当正压结构的异常信号.
当副极地锋偏北(南)时, 表面阿留申低压减弱(增强)( Taguchi等, 2012). 此外, 最近的研究指出, 副极地海洋 锋与中纬度大气风暴轴活动具有密切的关联(Hoskins 和 Valdes, 1990; Hoskins 和 Hodges, 2002; Nakamura等, 2004; Nakamura 和 Shimpo, 2004; Nakamura 和 Yamane, 2009, 2010). 在观测和数值模式模拟中, 北太平洋主 风暴轴中心总是锁定在副极地锋区的强海温梯度上 空(Nakamura等, 2004, 2008; Taguchi等, 2009). 如果在 数值模式强迫中去除副极地海洋锋, 北太平洋大气风 暴轴及其激发的极锋急流都将显著减弱 (Nakamura等, 2008; Sampe等, 2010). Hoskins 和 Valdes(1990)通过观 测资料分析, 提出一种海洋锋维持风暴轴活动的可能 机制: 当风暴活动经过海-陆边界以及西边界流区时, 在对流层低层和中层产生强烈的非绝热加热, 从而增 强北太平洋风暴轴入口处的大气斜压性并维持风暴 轴; 此外, 他们认为风暴轴活动所引起的大气风应力异 常可以增强海洋西边界暖流并维持海洋锋区, 这就构 成了一个自维持的系统. 而Nakamura等(2008)利用理 想的水球模式, 提出了另一种海洋锋维持风暴轴的可 能机制: 当气流跨越狭窄的海洋锋时, 锋区两侧显著 的表面感热通量的差异可以有效地回复由瞬变向极热 量输送减弱的中纬度大气斜压性, 维持中纬度大气风 暴轴的中心位置和强度. 这个机制被称为“海洋斜压 调整机制”(Nakamura等, 2008; Nonaka等, 2009; Hotta 和 Nakamura, 2011). Taguchi等(2009)利用区域模式验 证了海洋斜压调整机制在北太平洋地区副极地锋附 近的作用, 证实副极地锋的存在对于天气尺度扰动发 展和大气风暴轴、极锋急流的形成都有重要作用.

在北太平洋 $28^{\circ} \mathrm{N} \sim 32^{\circ} \mathrm{N}$ 还存在着另一只海盆尺度 的海洋温度锋 (副热带海洋锋), 它与海表面风应力驱 动的Ekman输送辐合密切相关, 且在冬季和春季可以 持续存在(Uda 和 Hasunuma, 1969; Roden, 1975). 副热 带海洋锋不仅能显著影响上空边界层大气和表面风速 (Xie, 2004), 也有利于大气深对流活动的产生(Kobashi 等, 2008). 然而, 关于副热带锋的变化与中纬度大气的 风暴轴活动有怎样的联系, 目前的研究还比较少. 此 外, Hoskins 等(1983)指出中纬度大气风暴轴活动(高 频扰动, 10 天以下)与大气低频扰动(10天以上)的结构 以及对平均流的反馈有显著的不同. 在北太平洋地区, 高频扰动在低层斜压发展且向高层向东传播, 增强风 暴轴区的西风; 而低频扰动相对于纬向流向西运动, 
其反馈作用减弱纬向西风的纬向非均匀性. 由于高频 扰动和低频扰动对大气平均态影响的明显差异, 本文 将分别研究副热带锋强度变化与高频(风暴轴)和低频 大气扰动异常及其反馈作用的关系.

\section{2 资料、模式和方法简介}

\section{1 观测资料}

本文对两套时空分辨率不同的海温同化资 料进行了海洋锋区的选定和对比分析. 第一种 为 HadISST(Hadley Center Global Sea Ice and Sea Surface Temperature) 月平均海温资料, 时间范围为 1960-01-01 2011-12-31, 水平分辨率为 $1^{\circ} \times 1^{\circ}$ (Rayner 等, 2003). 第二种为来自 NCDC/NOAA (National Oceanic and Atmospheric Administration's National Climatic Data Center) 的 OISST.V2 (Optimum Interpolation SST Version 2) 逐日海温资料 (Reynolds 等, 2007), 空间分辨率为 $0.25^{\circ} \times 0.25^{\circ}$. 它可以很好地 描述海洋锋区的细致结构, 但是时间范围较短, 为 1982-01-01 2011-12-31.

使用的大气观测资料为取自 NECP/NACR (National Centers for Environmental Prediction/National Center for Atmospheric Research)的全球大气再分析(R-1) 资料(Kalnay等, 1996). 取用常规气象变量包括大气温 度、位势高度、水平和垂直风速等. 该资料经纬网 格密度为 $2.5^{\circ} \times 2.5^{\circ}$, 垂直方向有 17 层气压层, 时间 分辨率为逐日, 时间长度从1960-01-01至2011-12-31. 另外还使用了WHOI (Woods Hole Oceanographic Institution) 提供的 OAFlux (Objectively Analyzed air-sea Fluxes) 月平均海气界面热通量资料中的感热和潜热 通量 (Yu等, 2008), 其水平分辨率为 $1^{\circ} \times 1^{\circ}$, 时间范围 为1960-01-01 2011-12-31.

本文的研究主要针对冬季, 定义为当年的 12 月到 次年的 1 月、 2 月, 将这 3 个月的数据平均, 即得到当年 的冬季平均值.

\section{2 模式简介}

本文使用的区域大气模式是 WRF 模式3.4.1版 (Advanced Research Weather Research and Forecasting Model system ARW version 3.4.1)(Skamarock等, 2005). WRF是一个准可压、非静力的中尺度模式. 关于WRF
模式的详细介绍可参见Skamarock等(2005). WRF模式 在中尺度、区域气候等方面的模拟受到广泛认可, 是 目前最先进的区域气象模式之一. 模式采用的物理参 数化方案包括: 微物理方案为Thompson等(2004)方案, 积云参数化方案为Betts-Miller-Janjić方案(Janjić, 1994, 2000), 陆面方案采用 Noah 陆面模式(Chen和Dudhia, 2001), 边界层方案为Yonsei大学边界层参数化方案 (Hong等, 2006), 长波辐射方案为快速辐射传输方案 (Mlawer等, 1997), 短波辐射方案为Dudhia方案(Dudhia, 1989). 模拟的水平范围为 $5^{\circ} \mathrm{N} \sim 60^{\circ} \mathrm{N}, 117^{\circ} \mathrm{E} \sim 117^{\circ} \mathrm{W}$, 水 平分辨率为 $50 \mathrm{~km}$, 垂直分为 28 个层.

为了对大气浴旋扰动有较好的模拟效果, 取用 NCEP/FNL 再分析资料作为 WRF 区域模 式的下边界以及大气边界进行模拟. NCEP/ FNL 再分析资料作为 NCEP 的一种数据产品 (http://rda.ucar.edu/datasets/ds083.2), 是WRF官网中推 荐使用的大尺度模拟数据, 具有较高的时空分辨率, 时 间分辨率为每 6 小时一次, 水平分辨率为 $1^{\circ} \times 1^{\circ}$, 垂直 方向 26 个气压层, 所取数据的时间范围为2000-01-01 2011-12-31. 利用随后所定义的副热带海洋锋指数 (本 文2.4章节), 选取了标准化的副热带锋强度指数 $>1$ 的 年份(2002年和 2005 年两个显著强个例年)作为副热带 锋偏强的年份, 标准化指数 $<-1$ 的年份 (2008年和 2010 年两个显著弱个例年)作为副热带锋偏弱的年份, 并 采用 NCEP/FNL资料下对应的海温场和大气边界场 强迫区域大气模式进行实景模拟(控制试验), 每次模 拟从当年 12 月 1 日起连续积分到次年 2 月 28 日. 在本 文选取的NCEP/FNL模式强迫资料场中, 副热带海洋 锋强弱年时的海温梯度差别主要体现在副热带海域 (图2c). 将模拟结果与观测结果进行比较分析, 检验在 NCEP/FNL资料强迫下, WRF区域大气模式能否重现 观测中出现的伴随副热带海洋锋强度变化的大气扰 动异常和平均场异常, 并为下一步具体探讨副热带锋 区异常对大气的影响提供基础. 控制实验包含了副热 带海洋锋强度的变化以及背景大气环流场的调整对 北太平洋上空大气场的影响可能. 另进行两组敏感性 试验, 保持副热带海洋锋区强、弱年的大气侧边界不 变, 将强弱年时的下垫面海温强迫场互换. 利用副热 带海洋锋区强(弱)年的大气侧边界条件配合副热带海 洋锋区弱(强)年的下边界海温条件进行数值模拟. 具 体数值试验设计如表 1 所示. 


\begin{tabular}{|c|c|c|}
\hline 数值试验分类 & 具体试验设计方案 & 试验名称 \\
\hline \multirow{2}{*}{ 两组控制实验 } & $\begin{array}{c}\text { 副热带海洋锋强年海温下边界+副热带海洋锋强年大气侧边界. 具体包 } \\
\text { 括: (2002年海温场+2002年大气侧边界、2005年海温场+2005年大气侧 } \\
\text { 边界), 将以上试验结果平均后代表本组试验. }\end{array}$ & 强年控制试验 \\
\hline & $\begin{array}{c}\text { 副热带海洋锋弱年海温下边界+副热带海洋锋弱年大气侧边界. 具体包 } \\
\text { 括: (2008年海温场+2008年大气侧边界、2010年海温场+2010年大气侧 } \\
\text { 边界), 将以上试验结果平均后代表本组试验. }\end{array}$ & 弱年控制试验 \\
\hline \multirow{2}{*}{ 两组敏感性试验 } & $\begin{array}{l}\text { 副热带海洋锋弱年海温下边界+副热带海洋锋强年大气侧边界. 具体包括: (2008年海温 } \\
\text { 场 }+2002 \text { 年大气侧边界、2008年海温场+2005年大气侧边界、2010年海温场+2002年大 } \\
\text { 气侧边界、2010年海温场+2005年大气侧边界), 将以上试验结果平均后代表本组试验. }\end{array}$ & $\begin{array}{l}\text { 强年边界弱年海 } \\
\text { 温敏感试验 }\end{array}$ \\
\hline & $\begin{array}{l}\text { 副热带海洋锋强年海温下边界+副热带海洋锋弱年大气侧边界. 具体包括: (2002年海温 } \\
\text { 场+2008年大气侧边界、2002年海温场+2010年大气侧边界、2005年海温场+2008年大 } \\
\text { 气侧边界、2005年海温场+2010年大气侧边界), 将以上试验结果平均后代表本组试验. }\end{array}$ & $\begin{array}{l}\text { 弱年边界强年海 } \\
\text { 温敏感试验 }\end{array}$ \\
\hline
\end{tabular}

利用以上的数值试验, 分别给出强年控制试验与 强年边界弱年海温敏感性试验的差值, 以及弱年边界 强年海温敏感性试验与弱年控制试验的差值. 从而探 讨伴随不同的大气侧边界, 强、弱副热带海洋锋年海 温强迫下, 区域模式中中纬度大气扰动活动和平均急 流强度的直接差异.

\section{3 高、低频大气扰动及其动力强迫和热力强迫 定义}

本文主要关注伴随副热带海表面温度锋强度变 化时, 大气中浴旋扰动的异常. 对于大气变量 $A$ 可分解 为冬季平均值 $\bar{A}$ 和相对于平均的扰动值 $A^{\prime}$, 扰动值可 分为经时间滤波快速傅里叶变换(FFT)后所对应的高 频扰动异常值(天气尺度瞬变, 2 7天)和低频扰动异常 值(10 90天).

利用扰动动能 $E K E=\left(u^{\prime 2}+v^{\prime 2}\right) / 2$ 的大小表示扰 动活动的强度, 其中 $u^{\prime} 、 v^{\prime}$ 分别为纬向风速和经向风 速的扰动值. 利用 $\mathrm{P}$ 坐标下大气水平运动方程、热流 量方程和连续方程:

$$
\begin{gathered}
\frac{\partial u}{\partial t}+\vec{V}_{h} \cdot \nabla_{h} u+\omega \frac{\partial u}{\partial p}=f v-\frac{\partial \Phi}{\partial x}+F_{x}, \\
\frac{\partial T}{\partial t}+\vec{V}_{h} \cdot \nabla_{h} T+\sigma_{0} \omega=\frac{Q}{C_{P}}, \\
\frac{\partial u}{\partial x}+\frac{\partial v}{\partial y}+\frac{\partial \omega}{\partial p}=0,
\end{gathered}
$$

其中 $\vec{V}_{h}$ 为水平风速矢, $\nabla_{h}=\frac{\partial}{\partial x}+\frac{\partial}{\partial y}, \omega$ 为垂直风速, $f$ 为科式参数, $\Phi$ 为位势高度, $F_{x}$ 为摩擦项, $T$ 为大气温
度, $C_{P}$ 为定压比热, $\sigma_{0}=\frac{1}{C_{P}} \frac{R T}{p}-\frac{\partial T}{\partial p}$ 为静力稳定度参 数, $Q$ 为非绝热加热, $R$ 为比气体常数.

对式(2)经向求导 $(-\partial / \partial y)$, 并将式(1)、(2)、(3)中 的每个变量都改写为时间平均项和扰动项的叠加, 整 理后可将方程改写为如下:

$$
\begin{gathered}
\frac{\partial \bar{u}}{\partial t}+\frac{\partial(\overline{u u})}{\partial x}+\frac{\partial(\bar{u} \bar{v})}{\partial y}+\frac{\partial(\bar{u} \bar{\omega})}{\partial p} \\
=f \bar{v}-\frac{\partial \bar{\Phi}}{\partial x}+\overline{F_{x}}-\frac{\partial\left(\overline{\left.u^{\prime} u^{\prime}\right)}\right.}{\partial x}-\frac{\partial\left(\overline{\left.u^{\prime} v^{\prime}\right)}\right.}{\partial y}-\frac{\partial \overline{\left(\bar{u}^{\prime} \omega^{\prime}\right)}}{\partial p}, \\
\frac{\partial}{\partial t}\left(-\frac{\partial \bar{T}}{\partial y}\right)-\frac{\partial}{\partial y}\left[\frac{\partial}{\partial x}(\bar{u} \bar{T})\right]-\frac{\partial}{\partial y}\left[\frac{\partial}{\partial y}(\bar{v} \bar{T})\right] \\
-\frac{\partial}{\partial y}\left[\frac{\partial}{\partial p}(\bar{\omega} \bar{T})\right]+\frac{\partial}{\partial y}\left[\frac{\bar{\sigma}}{C_{p}} \frac{R \bar{T}}{p}\right) \\
=-\frac{\partial}{\partial y}\left[\frac{\bar{Q}}{C_{P}}\right)+\frac{\partial}{\partial y}\left[\frac{\partial \overline{\left(u^{\prime} T^{\prime}\right)}}{\partial x}\right]+\frac{\partial}{\partial y}\left[\frac{\partial \overline{\left(v^{\prime} T^{\prime}\right)}}{\partial y}\right] \\
+\frac{\partial}{\partial y}\left[\frac{\partial \overline{\left(\omega^{\prime} T^{\prime}\right)}}{\partial p}\right]-\frac{\partial}{\partial y}\left(\frac{R}{C_{p}} \frac{\overline{\omega^{\prime} T^{\prime}}}{p}\right) .
\end{gathered}
$$

公式(4)中扰动通过动量输送对时间平均纬向风 速倾向的直接强迫作用

$$
\left(-\frac{\partial \overline{\left(u^{\prime} u^{\prime}\right)}}{\partial x}-\frac{\partial \overline{\left(u^{\prime} v^{\prime}\right)}}{\partial y}-\frac{\partial \overline{\left(u^{\prime} \omega^{\prime}\right)}}{\partial p}\right),
$$

记为扰动的直接动力强迫 (Ueddy). 公式(5)中扰动通 过输送热量对时间平均的大气经向温度梯度倾向的 直接强迫作用

$$
\left(\frac{\partial}{\partial y}\left[\frac{\partial \overline{\left(u^{\prime} T^{\prime}\right)}}{\partial x}\right]+\frac{\partial}{\partial y}\left[\frac{\partial \overline{\left(v^{\prime} T^{\prime}\right)}}{\partial y}\right]+\frac{\partial}{\partial y}\left[\frac{\partial \overline{\left(\omega^{\prime} T^{\prime}\right)}}{\partial p}\right]-\frac{\partial}{\partial y}\left(\frac{R}{C_{p}} \frac{\overline{\omega^{\prime} T^{\prime}}}{p}\right)\right),
$$


记为扰动的直接热力强迫 (Teddy). 依据时间滤波的结 果, 可将表征浴旋扰动的特征值(包括扰动动能, 动力 强迫和热力强迫)分解为低频扰动的部分、高频扰动 的部分, 以及交叉频扰动部分. 而交叉频扰动的部分 相对较弱(Nie等, 2013), 本文不做主要讨论.

\section{4 海洋锋强度定义及分析方法简介}

图1所示为冬季北太平洋海表面温度及其经向梯 度 $(-\partial S S T / \partial y)$ 气候平均态分布, 包括HadISST、OISST 和 $\mathrm{NCEP} / \mathrm{FNL}$ 三套海温数据. 海温经向梯度大值主要 位于中纬度地区的两条带状海洋锋区范围内, 分别为 $30^{\circ} \mathrm{N}$ 左右的副热带锋区, 以及 $40^{\circ} \mathrm{N}$ 左右的副极地锋区. 两条海洋锋区经向范围较窄, 而纬向延伸较宽, 几乎 跨越整个海盆 $\left(140^{\circ} \mathrm{E} \sim 140^{\circ} \mathrm{W}\right)$. 不同的海温资料中海温 梯度的空间分布特征基本一致, 只是在温度梯度强度 上略有差别, 都可以很好地表征冬季北太平洋地区大 尺度的海洋锋区的特征.

冬季北太平洋副热带海洋锋变化的主要模态表现 为其强度的变化(图略), 为了定量化表征副热带锋整 体的强度特征, 我们定义了一个副热带锋强度指数. 首 先, 将冬季气候态的海温经向梯度进行 $140^{\circ} \mathrm{E} \sim 140^{\circ} \mathrm{W}$ 范围的纬向平均, 得到如图2中黑色实线表示的海温 梯度随纬度的变化曲线. 海温梯度自 $20^{\circ} \mathrm{N}$ 向高纬逐渐 增强, 至 $28^{\circ} \mathrm{N}$ 附近达到第一个极大值, 随后向北略减 弱后又继续增强, 并在 $40^{\circ} \mathrm{N}$ 达到最大值. 这两个海温 梯度极大值出现的纬度, 分别对应着副热带海洋锋和 副极地海洋锋的中心位置. 对比图 $2 \mathrm{a} \sim \mathrm{c}$ 中不同海温资 料的纬向平均海温梯度, 除了海洋锋强度(主要是副 极地锋强度)略有差别, 其空间分布基本一致. 在本文 中, 将 $24^{\circ} \mathrm{N} \sim 32^{\circ} \mathrm{N}$ 范围内的纬向平均的海温梯度的平 均值, 定义为副热带锋的强度指数, 反映副热带锋范 围内整体的海温梯度的强弱. 当指数较大时 (副热带 锋范围内海温梯度整体较大时)对应副热带海洋锋较 强, 而指数较小时则对应副热带锋较弱. 利用定义的 副热带锋强度指数可以定量化的表征冬季北太平洋 副热带海洋锋的强度随时间的变化特征(图3).

对基于HadISST海温资料定义的冬季副热带海 洋锋强度指数(1960 2010年)进行标准化, 选取标准 化指数>1的年份(1960、1961、1976、1980、1983、 1986、1995、1997、2002、2005), 作为副热带锋偏
强的年份, 标准化指数 $<-1$ 的年份为副热带锋偏弱年 份(1964、1971、1989、1990、1992、1994、1999、 2008、2010). 将副热带锋偏强、偏弱年的大气异常场 分别进行合成, 研究与副热带海洋锋强度变化有关的 大气异常信号

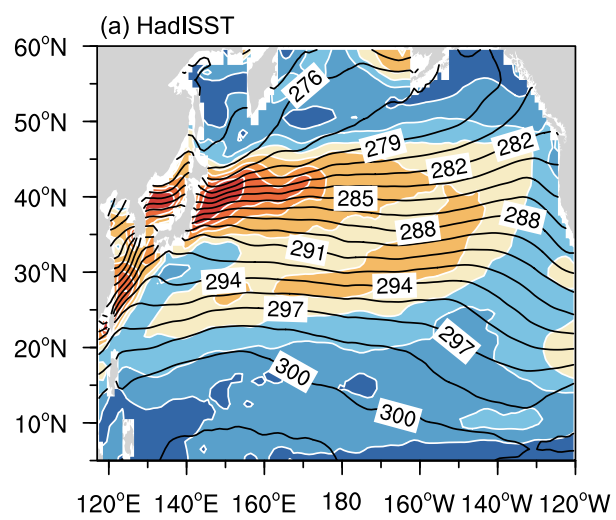

(b) OISST
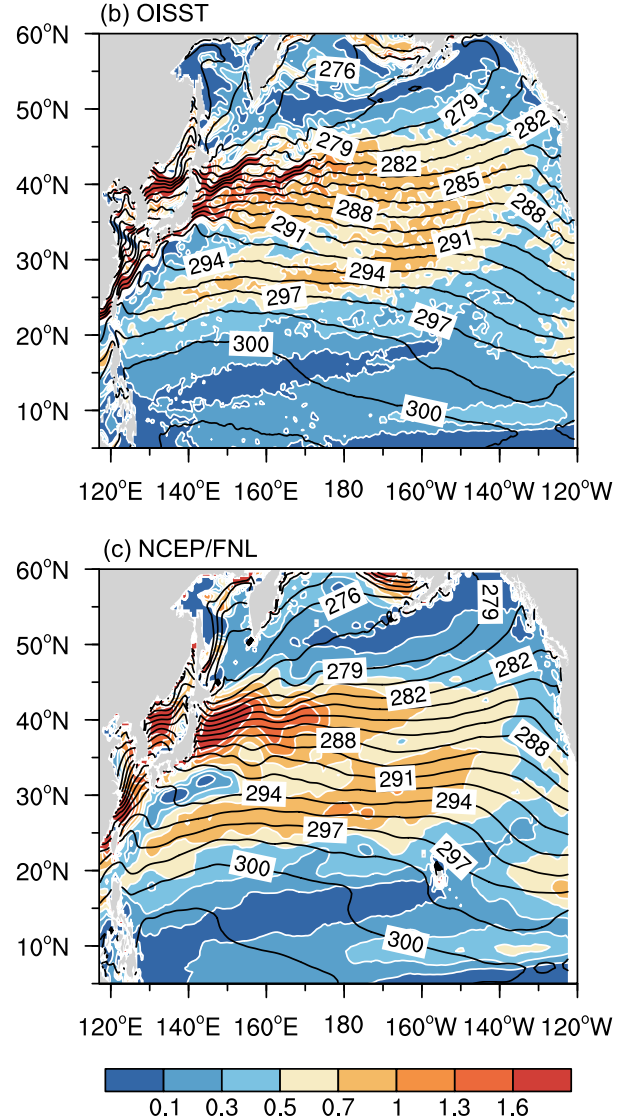

图 1 冬季北太平洋海表面温度及其经向梯度分布 (a) HadISST 数据下的冬季平均态; (b) OISST 数据; (c) NCEP/FNL 数据. 温度单位: $\mathrm{K}$; 梯度单位: $10^{-5} \mathrm{~K} \mathrm{~m}^{-1}$ 
为了进一步验证副热带海洋锋的强度变化与局 地大气异常的关系, 本文利用 NCEP/FNL数据时长范 围内, 副热带海洋锋偏强(2002、2005)和偏弱 (2008、 2010)年份的NCEP/FNL冬季海温场和大气边界场驱 动区域大气模式进行实景模拟(控制试验), 每次模拟 从当年 12 月 1 日连续积分到次年 2 月 28 日. 将副热带海 洋锋偏强年和偏弱年的大气响应分别进行合成, 得到 数值试验中伴随副热带锋强度变化的大气异常响应 型分布特征, 并与观测结果进行对比分析. 此外, 利用 副热带海洋锋区强(弱)年的大气侧边界条件配合副热 带海洋锋区弱(强)年的下边界海温条件进行数值模拟 (敏感性试验), 与控制试验对比分析, 探讨副热带海洋 锋强度对大气的直接影响.

\section{3 伴随副热带锋强度变化的大气异常特征}

\section{1 海温梯度在副热带海洋锋偏强、偏弱年的合 成}

利用本文第二部分中定义的副热带海洋锋强度指 数, 将HadISST的海温经向梯度在副热带锋偏强、偏 弱年分别进行合成. 纬向平均的海温梯度在副热带锋 偏强/弱年的合成如图2a中红色/蓝色虚线所示, 采用 HadISST数据下的副热带海洋锋强度变化与OISST(图 $2 b$ )和NCEP/FNL(图2c)两套数据的结果一致. 在OISST 数据下, 在副热带海洋锋强度偏强时副热带海洋锋 主要表现为双峰的结构, 而在其总体强度偏弱时表 现为单峰的结构. 这一现象是在OISST中独有的, 在 HadISST和NCEP/FNL数据的合成结果中均没有表现,
这可能与资料的空间分辨率有关. 在 NCEP/FNL 数据 的强弱年合成结果中, 海温梯度的异常主要位于副热 带海域内, 而其他海域内(尤其是副极地锋范围内)的 海温梯度变化较小。

\section{2 海温和大气环流与副热带海洋锋强度的关系}

SST在副热带海洋锋偏强、偏弱年合成的异常(图 $4 a 、 e 、 i)$ 指出, 副热带海洋锋的强度变化与太平洋区 域大尺度的海温异常型有密切关联. 当副热带海洋 锋偏强(弱)时, 海表面温度异常的空间型表现为类似 PDO正(负)位相的大尺度海温异常. 副热带海洋锋强 度指数与PDO指数在年际变化时间尺度上也存在较 高的同期正相关关系(图3b), 但副热带海洋锋强度指 数的年代际变化特征并不显著. 而副热带海洋锋的强 度变化与热带太平洋ENSO事件并没有显著的同期相 关性(图3a).

图4还给出海表面气压(SLP)、500hPa 风暴轴(以 $500 \mathrm{hPa}$ 位势高度2 7天滤波均方差表示)和 $300 \mathrm{hPa}$ 位势 高度在副热带锋偏强年、偏弱年异常的合成结果. 在 中纬度北太平洋上空, 副热带海洋锋偏强(弱)时, 北太 平洋SSTA为PDO正(负)位相. 冷异常(暖异常)的洋面 上空, 对应着海表面气压场的低压(高压)异常, 即阿留 申低压的强度增强(减弱). 在垂直方向上, 高度场异常 为相当正压结构, 在对流层中高层, 大气高度场异常 为PNA正位相(负位相). 海气系统在垂直方向上表现 为冷槽(暖脊)结构的配置. 同时, 北太平洋上空的风暴 轴活动在其入口以及中心区域强度增强(减弱).
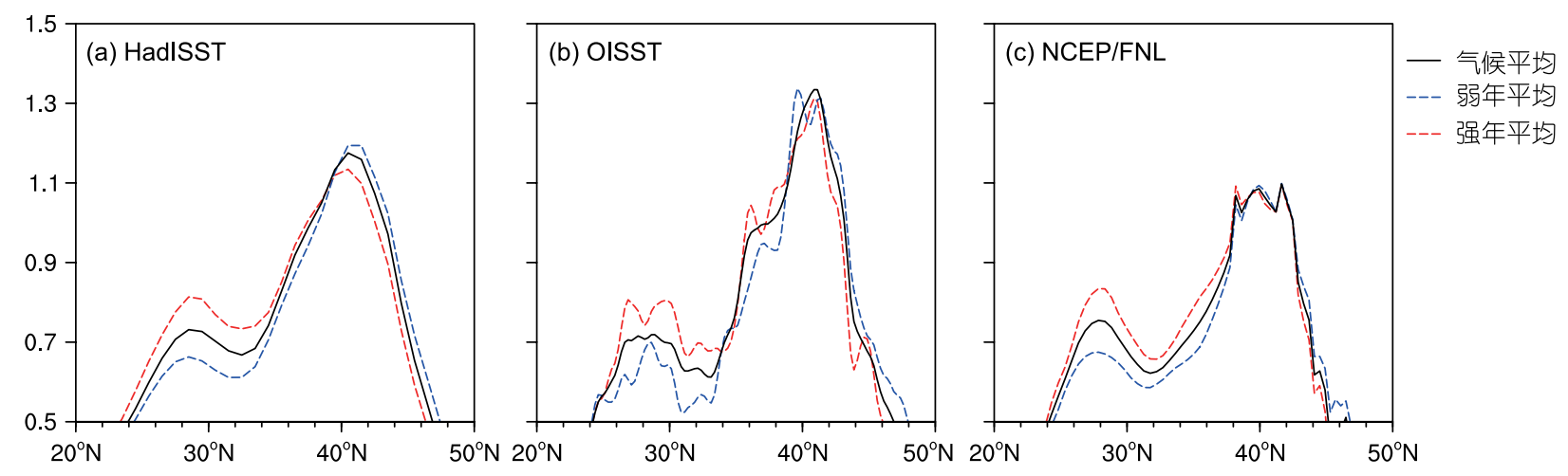

图 $2140^{\circ} \mathrm{E} 140^{\circ} \mathrm{W}$ 纬向平均的 SST 经向梯度在副热带海洋锋偏强年的合成、偏弱年的合成以及冬季气候平均态 (a) HadISST数据; (b) OISST数据; (c) NCEP/FNL数据. SST经向梯度单位: $10^{-5} \mathrm{~K} \mathrm{~m}^{-1}$ 

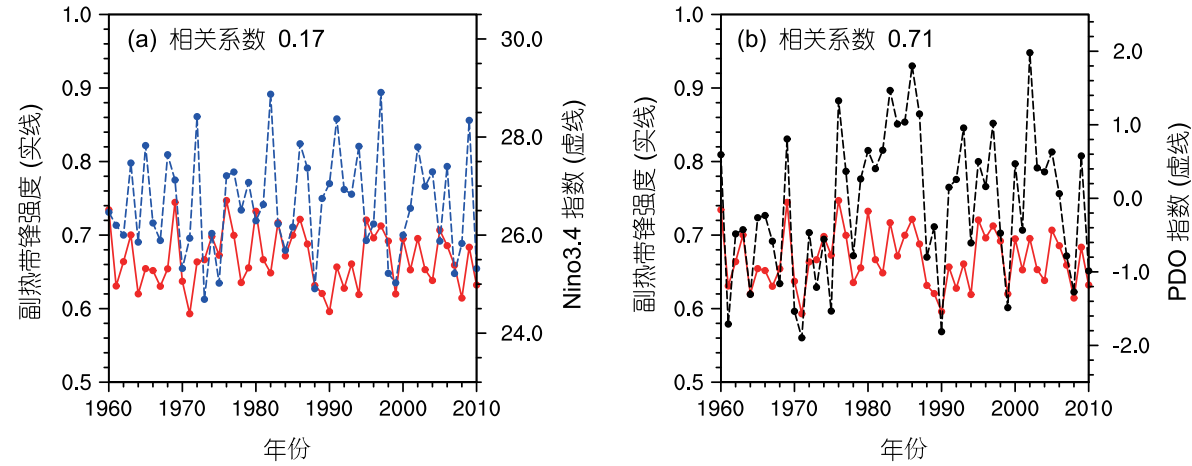

图 3 1960 2010年冬季平均的副热带海洋锋强度指数与Nino3.4指数(a)、PDO指数(b)的分布

副热带锋强度指数与Nino3.4指数的相关系数为 0.17 , 与 PDO指数的相关系数为 0.71 . 满足 $95 \%$ 信度 $t$ 检验的临界相关系数为 0.28

(a) 海温 强年异常

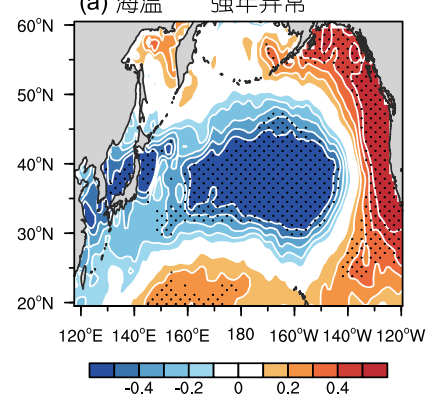

(e) 海温弱年异常


(b) 海平面气压 强年异常
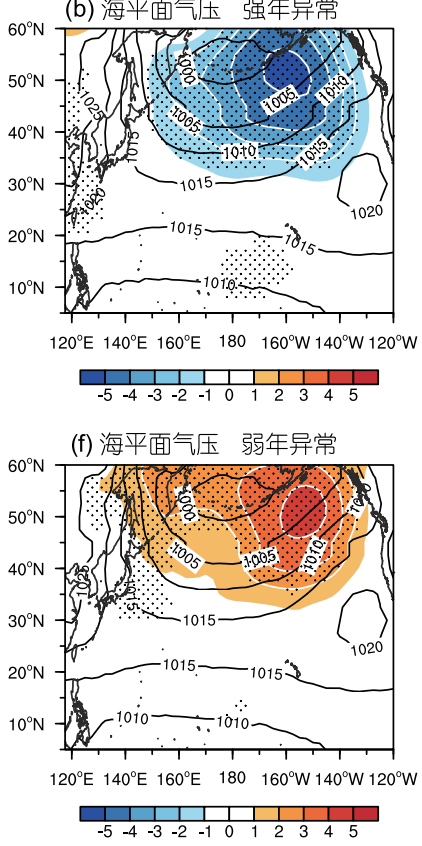

(j) 海平面气压 强-弱

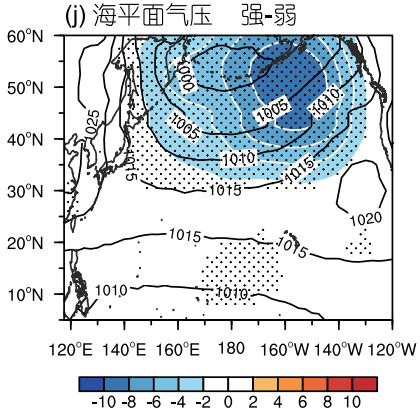

(c) 高度场 强年异常

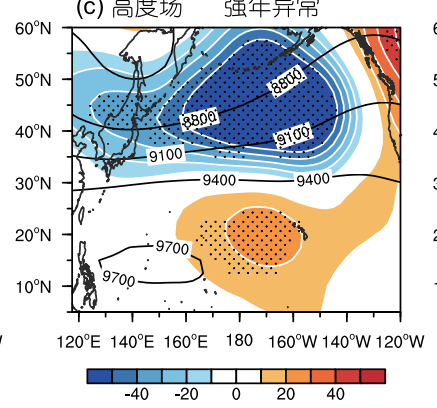

(g) 高度场 弱年异常

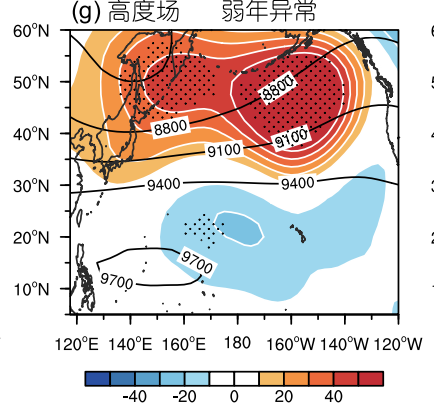

(k) 高度场 强-弱



(d) 风暴轴 强年异常

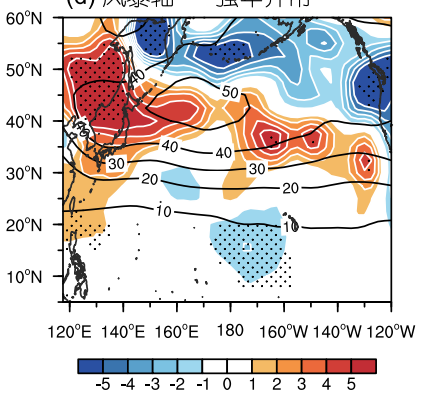

(h) 风暴轴 弱年异常

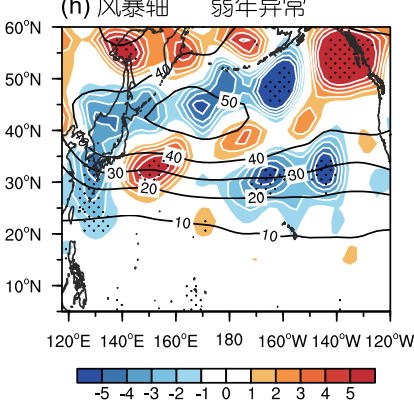

(I) 风暴轴强-弱

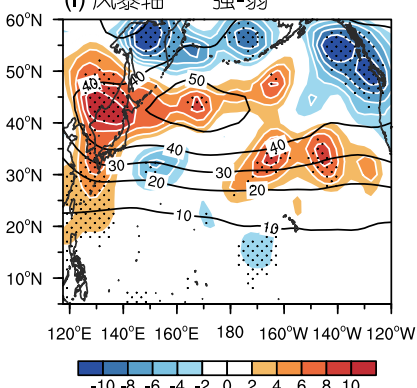

图 4 海表面温度、海表面气压、300hPa高度场、500hPa 风暴轴的合成与气候平均态的差

(a) 海表面温度(单位: K); (b) 海表面气压(单位: hPa); (c) $300 \mathrm{hPa}$ 高度场(单位: gpm); (d) $500 \mathrm{hPa}$ 风暴轴(单位: gpm) 在副热带锋偏强年的合成 与气候平均态的差, 等值线为气候平均态. (e) (h) 同 (a) (d), 只是填色为副热带锋偏弱年合成与气候态平均态的差. (i) ( (l) 同 (a) (d), 只是为 副热带锋偏强年合成与偏弱年合成的差异. 阴影标出通过信度检验的区域 


\section{3 大气温度梯度和扰动动能与副热带海洋锋强 度的关系}

Hoskins等(1983)指出高、低频大气扰动的结构和 对平均流的反馈有显著的不同. 因此, 我们分别研究 伴随副热带海洋锋强度变化, 大气高、低频扰动活动 的变化特征. 对应于SST经向梯度分布, 大气经向温度 梯度在中纬度区域 $\left(30^{\circ} \mathrm{N} \sim 40^{\circ} \mathrm{N}\right)$ 最强(图 $5 \mathrm{a}$ ). 已有研究 表明大气自身的斜压性与大气经向温度梯度密切相 关 $\left(\sigma_{B I} \sim-\partial T / \partial y\right.$, Lindzen和 Farrell, 1980). 大气斜压 不稳定度也在中纬度地区最强, 表示此处有大的平均 有效位能向扰动动能转化的可能, 有利于大气扰动活 动的发展. 大气扰动活动的强弱可由扰动动能(EKE) 的大小表示, 按照扰动频率分为低频(10 90天)和高频 (2 7天) 扰动, 图 $5 \mathrm{~b} 、 \mathrm{c}$ 中等值线分别给出了低频、高 频扰动动能的冬季气候态分布, 可以看出, 高、低频 扰动都在对流层高层(300 200hPa)的中纬度地区最强. 其中, 低频扰动的扰动动能(图5b)强于高频扰动, 且经 向延伸范围也更大. 在控制试验中, 大气温度梯度和
扰动 $E K E$ 的冬季气候态(图 $5 \mathrm{~d} \sim 5 \mathrm{f}$ )与观测基本一致, 只 是扰动动能更大. 这应该是由于模式分辨率高于观测 资料, 对于大气扰动的描述能力比观测资料更强.

伴随副热带海洋锋强度的变化, 中纬度大气经向 温度梯度(大气斜压性) 以及大气扰动活动的强度都有 明显的变化. 图5a所示为纬向平均的大气经向温度梯 度在副热带锋偏强年、偏弱年合成的差异. 其结果表 明, 副热带锋偏强时, 中纬度 $\left(30^{\circ} \mathrm{N} \sim 40^{\circ} \mathrm{N}\right)$ 大气温度梯 度整体显著偏强, 对应中纬度大气斜压性也偏强, 并 对中高层大气扰动动能的分布产生显著影响. 实际大 气中低频、高频扰动动能的变化与中纬度大气斜压 性增强之间的关系并不一致. 如图 $5 \mathrm{~b} 、 5 \mathrm{c}$ 所示, 当副 热带锋偏强(对应大气斜压性增强)时, 大气低频扰动 动能显著减弱, 尤其是在低频扰动动能气候态大值中 心的南北两侧最为明显, 而大气高频扰动动能异常表 现为在气候态大值中心两侧减弱而中心处显著增强 的特征. 利用模式模拟的中纬度大气高低频扰动动能 的异常分布也与观测基本一致(图5d 5f).
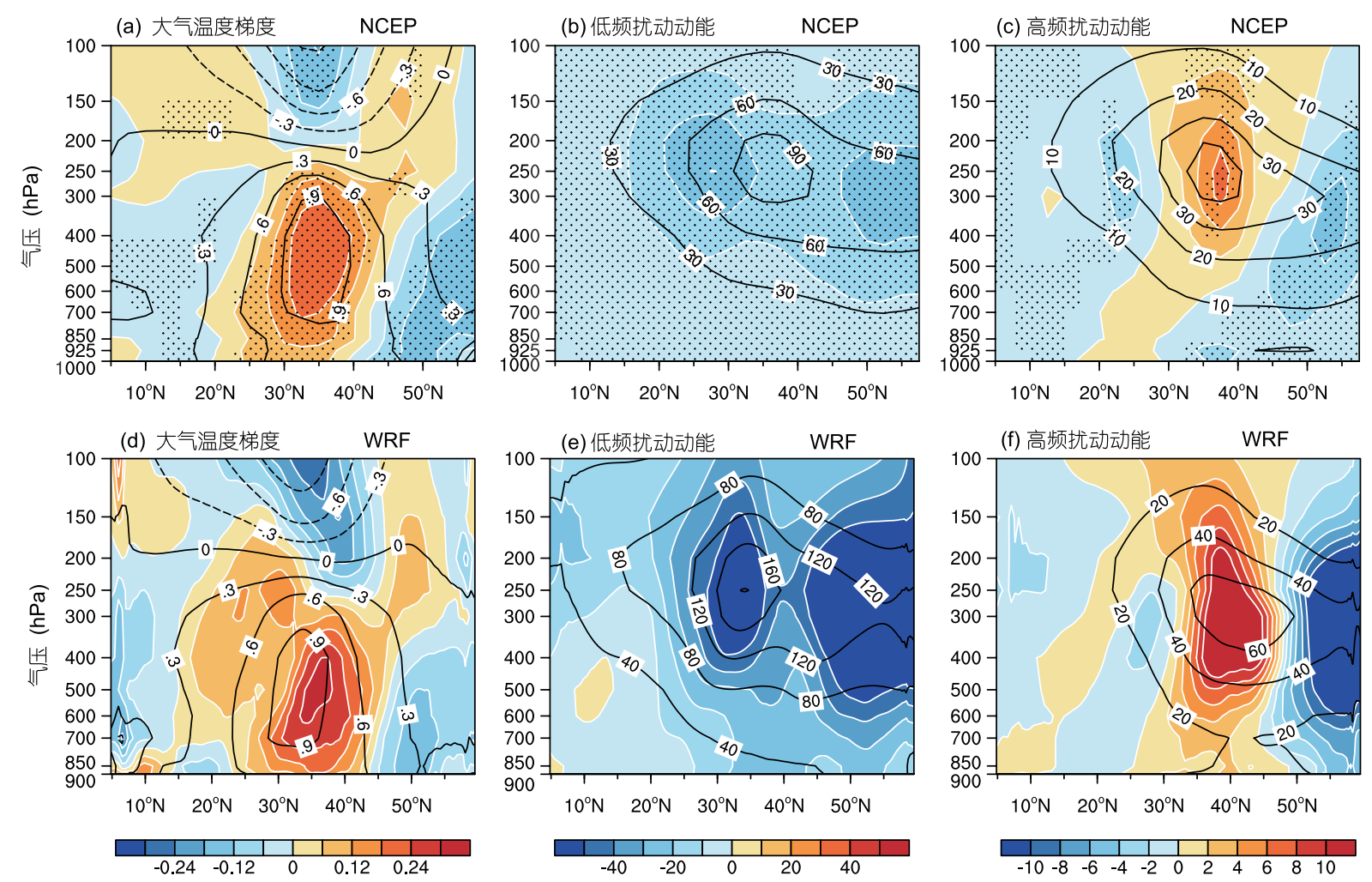

图 $5140^{\circ} \mathrm{E} \sim 140^{\circ} \mathrm{W}$ 纬向平均的大气变量冬季平均态及其在副热带锋偏强年、偏弱年合成的差

(a) 观测大气温度梯度(单位: $10^{-5} \mathrm{~K} \mathrm{~m}^{-1}$ ), (b) 观测大气低频扰动动能(单位: $\mathrm{m}^{2} \mathrm{~s}^{-2}$ ), (c) 观测大气高频扰动动能(单位: $\mathrm{m}^{2} \mathrm{~s}^{-2}$ ). 等值线表示平均 态. (d) (f) 同(a) ( c), 只是为控制试验的结果. 阴影为通过 $t$ 检验的区域 
在中纬度地区, 旺盛的大气扰动活动可以系统性 的输送动量和热量, 使得它们在大气中重新分布(如式 (4)、(5)所示). 大气扰动的动力强迫 (对动量平均态的 影响)和热力强迫(对温度平均态的影响)是形成对流 层大气环流的重要原因之一. 伴随副热带海洋锋的强 度变化, 中纬度大气斜压性强度发生变化, 引起了不 同的大气高、低频扰动活动的异常响应(副热带海洋 锋偏强时, 大气斜压性偏强, 高频扰动动能增加, 低频 扰动动能减弱). 这种不同的大气高、低频扰动异常 是否对应着不同的扰动动力强迫和热力强迫异常呢?

\section{4 中纬度大气扰动动力强迫与热力强迫的冬季 平均态分布}

在中纬度地区, 大气纬向风场具有显著的垂直风 切变, 强盛的大气斜压性有利于产生旺盛的短时间尺 度的大气扰动活动, 而短时间内发生的各种扰动又可 通过通量输送反作用于时间平均流, 形成对大尺度环
流的强迫作用. 中纬度大尺度环流与中纬度大气扰动 强迫之间有密切联系, 而冬季位于东亚-北太平洋上空 的西风急流作为中纬度大尺度环流中的重要组成部 分, 与中纬度大气扰动强迫紧密关联. 在北太平洋上 空, 冬季气候态的西风急流极大值中心约位于 $200 \mathrm{hPa}$, $30^{\circ} \mathrm{N}$ 左右的中纬度地区(图6d等值线). 正如已有研究 所揭示, 该急流在垂直方向上呈相当正压结构分布, 随着高度的降低, 急流的大值中心位置略向北移(图 略), 风速值快速减小且具有显著的垂直切变(Peixoto 和 Oort, 1992). 在250hPa等压面上(图6a等值线), 北太 平洋上空的急流强中心位于 $30^{\circ} \mathrm{N}$ 左右北太平洋西部, 纬向风速可达 $60 \mathrm{~m} \mathrm{~s}^{-1}$ 以上, 急流的水平分布具有明显 的纬向非均匀性.

如式(4)所示, 大气中的扰动活动可以通过动量输 送影响平均流的变化(倾向). 这种扰动对平均流的动 力强迫作用的气候态平均分布如图6(填色)所示, 其中 低频、高频扰动的动力强迫作用有显著的不同. 如图 (a) 纬向风\&动力强迫（低频） NCEP

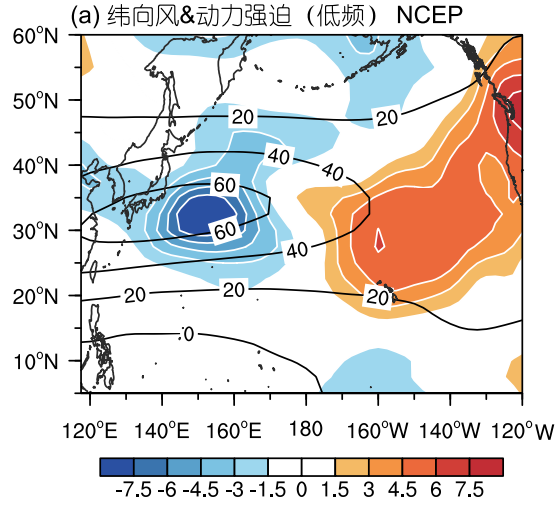

(d) 纬向风\&动力强迫（低频） NCEP

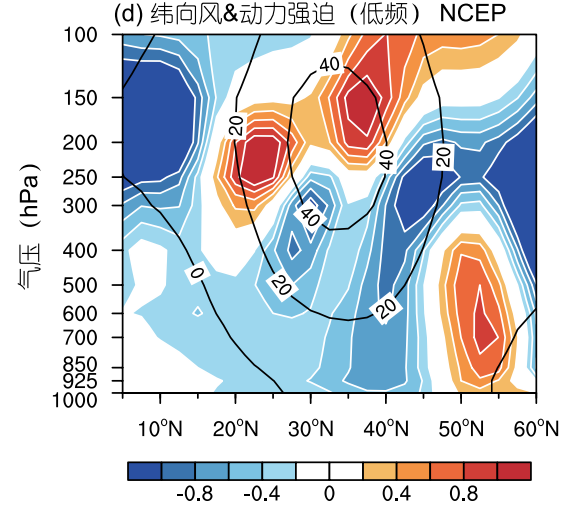

(b) 纬向风\&动力强迫（高频） NCEP

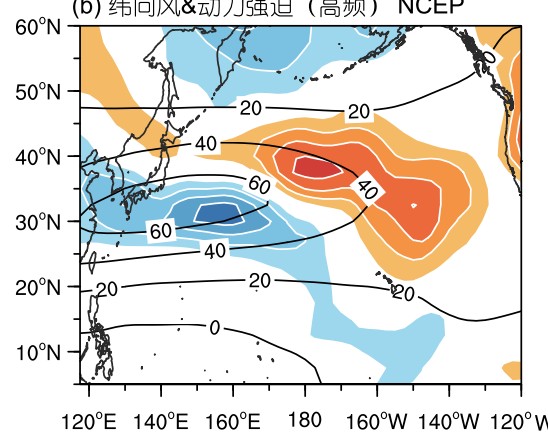



(e) 纬向风\&动力强迫 (高频) NCEP

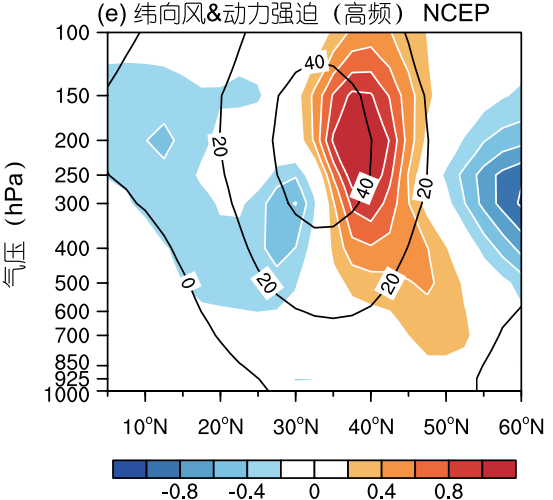

(c) 纬向风\&动力强迫 (高频) WRF


图 6 纬向风速和扰动动力强迫的冬季平均态

(a) 观测大气 $250 \mathrm{hPa}$ 纬向风速(等值线, 单位: $\mathrm{m} \mathrm{s}^{-1}$ ) 和低频扰动动力强迫(填色, 单位: $10^{-5} \mathrm{~m}^{2} \mathrm{~s}^{-2}$ ); (d) $140^{\circ} \mathrm{E} \sim 140^{\circ} \mathrm{W}$ 纬向平均的观测大气纬向 风速和低频扰动动力强迫的高度-纬度分布. (b)、(e)同(a)、(d), 填色表示观测大气高频扰动的动力强迫. (c)、(f)同(b)、(e), 为控制试验的 纬向风速和高频扰动动力强迫结果 
$6 \mathrm{a}$ 所示, $250 \mathrm{hPa}$ 等压面上低频扰动动力强迫在北太平 洋西部(急流中心)为负, 东部(急流中心下游)为正, 表 示低频扰动通过其动力强迫作用减弱急流强中心处 的纬向风速, 而增强下游地区的风速, 从而减弱西风 急流分布的纬向非均匀性(Hoskins等, 1983). 高频扰 动的动力强迫 (图6b)在急流强中心处为负, 而在急流 中心北部 $\left(35^{\circ} \mathrm{N} \sim 45^{\circ} \mathrm{N}\right)$ 以及下游地区为正, 表明高频扰 动减弱急流入口及南部的纬向风速, 而增强急流中心 北侧以及下游的风速, 且在垂直方向上为相当正压结 构(图6e), 有利于整层西风的加速. 本文采用数值模式 进行的实景模拟结果, 在扰动动力强迫特征及其与急 流之间的关系方面与观测结果一致 (图6c、f), 下文中 将采用该模式继续讨论伴随副热带海洋锋的强度变 化, 中纬度大气扰动的动力强迫以及平均气流的变化.

中纬度大气扰动除了可以通过动量输送影响时 间平均流(如式(4)), 还可以直接通过热量输送, 影响 中纬度大气的平均温度, 造成大气经向温度梯度 (大 气斜压性)的异常(如式(5)), 而大气斜压性异常又会对
大气扰动活动产生影响. 中纬度大气经向温度梯度与 中纬度大气扰动的热力强迫作用之间有密切的关联. 在北太平洋上空, 大气经向温度梯度的冬季平均态如 图7等值线所示, 在对流层内, 纬向平均的大气温度梯 度(图7d) 在中纬度 $30^{\circ} \mathrm{N} \sim 40^{\circ} \mathrm{N}$ 最强. 在 $600 \mathrm{hPa}$ 等压面 上, 大气温度梯度强中心位于 $30^{\circ} \mathrm{N} \sim 40^{\circ} \mathrm{N}$ 左右的西北 太平洋(图7a), 有利于大气扰动经过此处时快速发展 (Lindzen和 Farrell, 1980).

中纬度旺盛的大气扰动可以系统性地输送热量, 影响季节平均大气温度梯度倾向. 这种扰动对大气温 度梯度场的热力强迫作用的气候态分布如图7所示. 区别于高、低频扰动动力强迫的显著差异, 其热力强 迫差别不大. 总体表现为, 在对流层中层 $600 \mathrm{hPa}$ 等压 面上), 低频扰动热力强迫(图7a)在温度梯度强中心(尤 其是西北太平洋)为负,而在两侧为正, 且在垂直方向 上为相当正压结构, 表明扰动活动有利于减弱中纬度 整层的大气经向温度梯度(大气温度锋), 消弱中纬度 大气原有的斜压性. 高频扰动热力强迫的分布特征与 (a) 温度梯度\&热力强迫（低频） NCEP

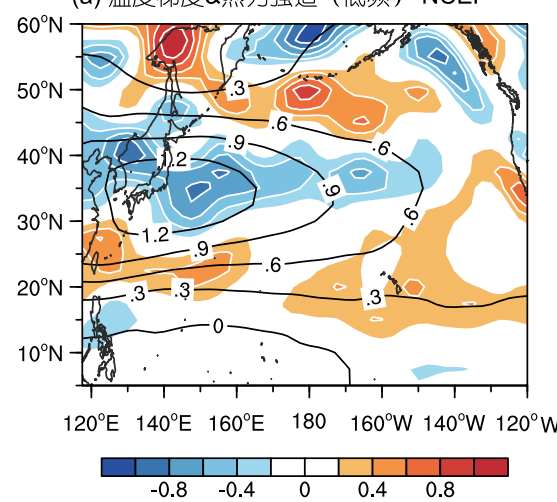

(d) 温度梯度 \&热力强迫 (低频) NCEP



(b) 温度梯度\&热力强迫（高频） NCEP



(e) 温度梯度\&热力强迫（高频） NCEP

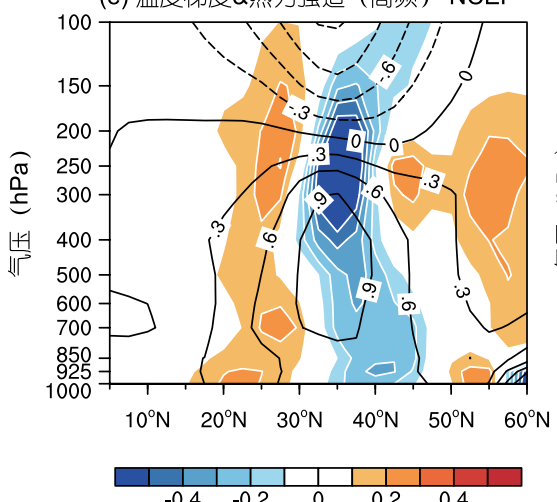

(c) 温度梯度\&热力强迫 (高频) WRF

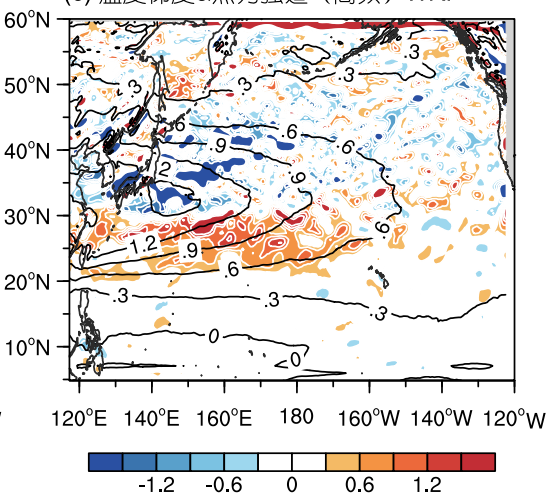

(f) 温度梯度\&热力强迫 (高频) WRF

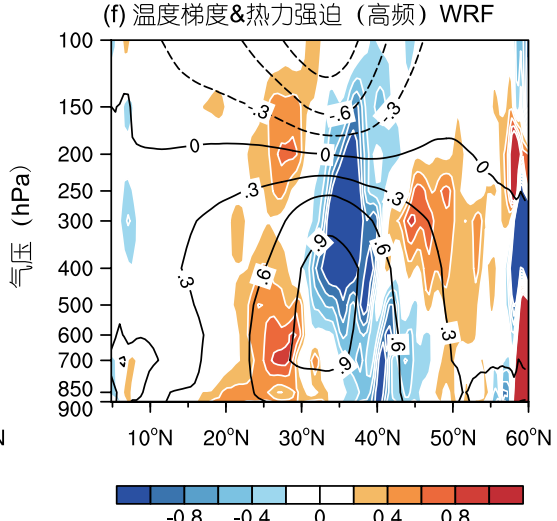

图 7 大气经向温度梯度和扰动热力强迫的气候态平均

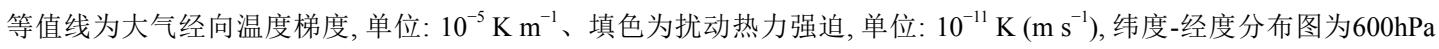


低频扰基本一致, 只是其零线位置略偏北. 在对流层低 层, 高频扰动使大气温度锋中心强度减弱且向南偏移. 随高度增加, 热力强迫略向南倾斜(图7e), 削弱对流层 中高层的中纬度大气温度锋. 我们利用WRF模式的实 景模拟中, 扰动热力强迫特征及其与大气温度梯度的 关系也与观测结果一致 (图7c、7f), 都表现为扰动的 直接热力强迫减弱中纬度大气斜压性, 不利于扰动的 持续发展. 因此, 下文中将继续采用该模式研究伴随 副热带海洋锋强度变化的大气扰动热力强迫的异常.

\section{5 中纬度大气扰动动力强迫、热力强迫与副热 带海洋锋强度的关系}

已有的研究指出中纬度大气平均流的变化与海 表面温度(或海温经向梯度)的变化有很好的对应关系 (朱伟军和孙照渤, 1999; 任雪娟等, 2007; Nakamura和 Yamane, 2010). 那么, 伴随副热带海洋锋强度的显著 变化, 大气平均流场有怎样的变化呢? 其中大气高、
低频扰动的强迫作用又分别起了怎样的作用呢?

利用合成分析纬向风速和扰动动力强迫在副热 带锋强年和弱年的差异, 结果如图8所示. 当副热带锋 偏强时, 纬向西风异常在北太平洋中、东部(冬季气候 态急流中心的下游地区)为正, 此时急流中心偏北、偏 东且增强(图8a). 在垂直方向上, 纬向平均的急流异常 表现为在 $30^{\circ} \mathrm{N} \sim 40^{\circ} \mathrm{N}$ 相当正压结构的增强(图 $8 \mathrm{~d}$ ).

对应于急流变化, 在副热带锋强度变化时, 高、低 频扰动动力强迫异常有差异明显(图8). 副热带海洋锋 偏强时, 低频扰动动能减弱, 低频扰动对纬向风倾向的 强迫(图8a)在太平洋西部为正异常, 在北太平洋中部 为负异常, 即低频扰动动力强迫偏弱(对比其冬季气候 态图6a), 不利于急流中心下游区域西风风速的加强和 急流的纬向均匀化. 而副热带海洋锋偏强时, 高频扰 动动能增强, 对应的动力强迫异常 (图 $8 \mathrm{~b}$ )在 $30^{\circ} \mathrm{N}$ 西太 平洋区域为负异常, 在急流中心北部 $35^{\circ} \mathrm{N} \sim 45^{\circ} \mathrm{N}$ 以及 下游东太平洋地区为正异常, 进一步增强急流中心北 (a) 纬向风\&动力强迫（低频） NCEP

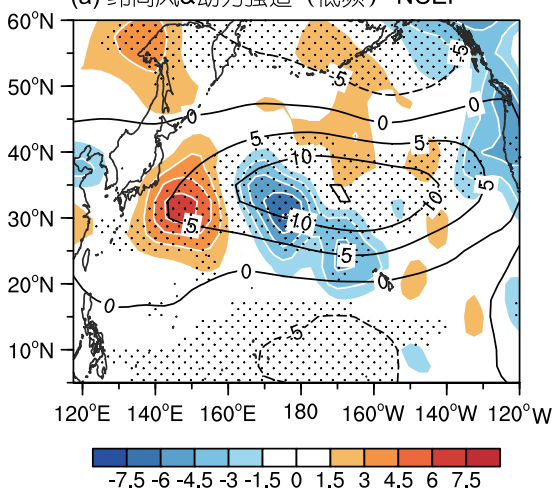

(d) 纬向风\&动力强迫（低频） NCEP



(b) 纬向风\&动力强迫（高频） NCEP

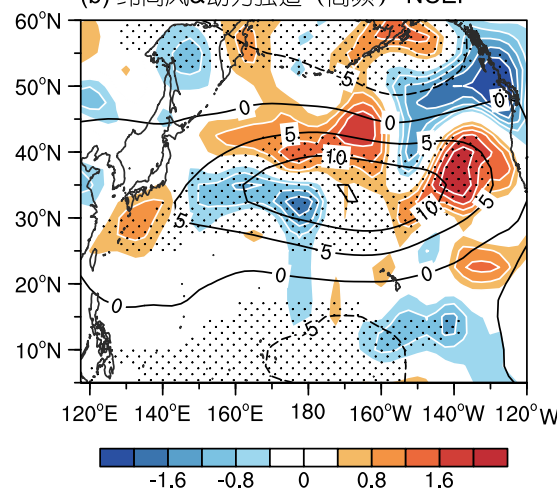

(e) 纬向风\&动力强迫 (高频) NCEP

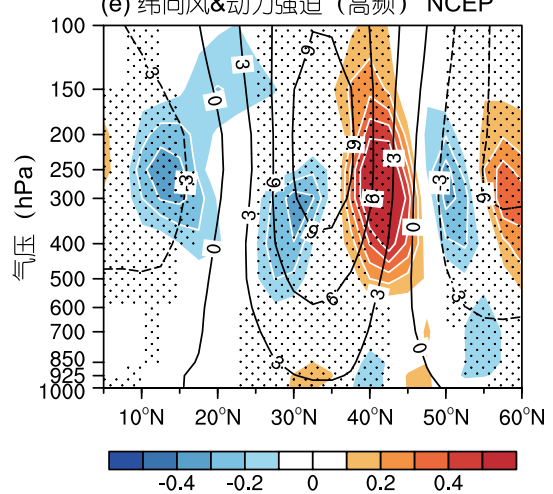

(c) 纬向风\&动力强迫 (高频) WRF

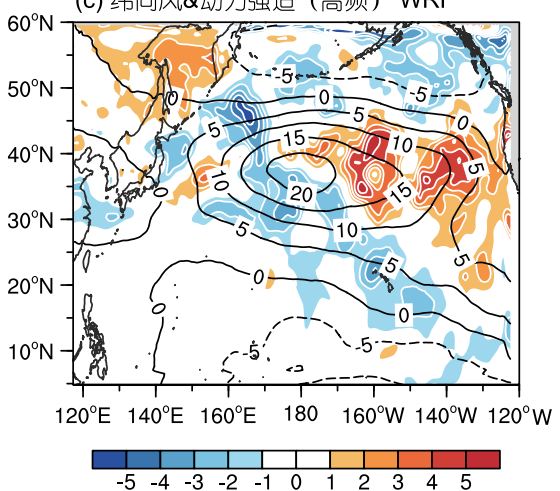

(f) 纬向风\&动力强迫（高频）WRF

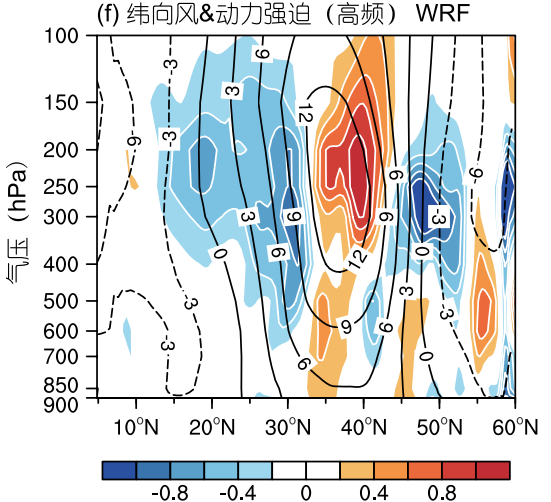

图 8 纬向风速和扰动动力强迫在副热带锋偏强年、偏弱年合成的差

(a) 观测大气 $250 \mathrm{hPa}$ 纬向风速(等值线,单位: $\mathrm{m} \mathrm{s}^{-1}$ )和低频扰动动力强迫(填色, 单位: $10^{-5} \mathrm{~m} \mathrm{~s}^{-2}$ ); (d) $140^{\circ} \mathrm{E} 140^{\circ} \mathrm{W}$ 纬向平均的观测大气纬向 风速和低频扰动动力强迫的高度-纬度分布. (b)、(e)同(a)、(d), 填色表示观测大气高频扰动的动力强迫. (c)、(f) 同(b)、(e), 为控制试验的 纬向风速和高频扰动动力强迫结果. 阴影为通过 $t$ 检验的区域 
侧和下游地区的纬向风速, 有利于形成如图 $8 b$ 所示的 急流异常增强的分布特征. 纬向平均的高频扰动动 力强迫异常在 $35^{\circ} \mathrm{N} \sim 45^{\circ} \mathrm{N}$ 为相当正压结构的正异常, 有利于急流中心及北侧整层西风的加速(图8e). 对比 高、低频扰动动力强迫异常与平均纬向风异常的分 布特征可以发现, 在副热带锋偏强时, 主要是高频扰 动的动力强迫异常有利于形成平均风增强的特征分 布. 数值试验中, 利用副热带海洋锋强、弱年的海温 分别作为下边界强迫区域大气模式进行实景模拟, 在 北太平洋上空重现了与观测一致的西风急流异常和 扰动动力强迫异常 (图8c、8f). 在图 $8 \mathrm{f}$ 中, 模式中纬向 平均的高频扰动动力强迫异常与纬向风的增强中心 具有非常好的符合, 表明伴随着副热带海洋锋强度的 变化, 平均纬向风速的变化特征主要是由高频扰动的 动力强迫异常所贡献.

当副热带海洋锋偏强时, 中纬度大气经向温度梯 度中心强度在对流层中整体增强(图9a、9d等值线). 中纬度大气扰动对大气温度梯度倾向项的直接热力 强迫也有明显的变化, 且高、低频扰动的热力强迫异
常存在明显差异(图9). 副热带锋偏强时, 纬向平均的 低频扰动热力强迫异常在对流层低层 $20^{\circ} \mathrm{N} \sim 30^{\circ} \mathrm{N}$ 为正 异常, 而在 $30^{\circ} \mathrm{N} \sim 40^{\circ} \mathrm{N}$ 为负异常, 进一步削弱大气锋北 侧的温度梯度, 使大气锋减弱并南移. 随着高度增高, 热力强迫异常向北倾斜. 至对流层中高层, 低频扰动 热力强迫在大气温度锋中心为正异常, 即对大气锋的 削弱作用偏弱, 有利于中纬度经向温度梯度的维持(图 $9 a 、 9 d)$. 高频扰动的热力强迫异常 (图9b、9e) 在对流 层内 $30^{\circ} \mathrm{N} \sim 40^{\circ} \mathrm{N}$ 为负异常, 且垂直方向呈相当正压结 构, 进一步削弱中纬度的大气斜压性. 对比高、低频 扰动热力强迫异常与平均大气经向温度梯度异常的 分布特征, 可以发现, 在副热带锋偏强时, 主要是低频 扰动的热力强迫异常有利于维持中纬度大气温度梯 度. 数值试验的结果(图9c、9f)与观测一致.

在控制试验中, 副热带锋强、弱年的大气扰动活 动和环流场异常均与观测结果一致, 表明在NCEP/FNL 资料强迫下, WRF区域大气模式的控制试验可以很好 的再现观测中出现的伴随副热带海洋锋强度变化的大 气异常. 因此控制试验可以合理的验证观测中伴随副 (a) 温度梯度＆热力强迫（低频） NCEP

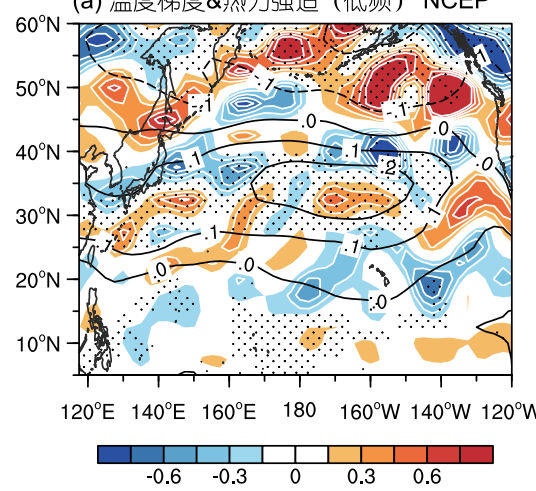

(d) 温度梯度\&热力强迫（低频） NCEP

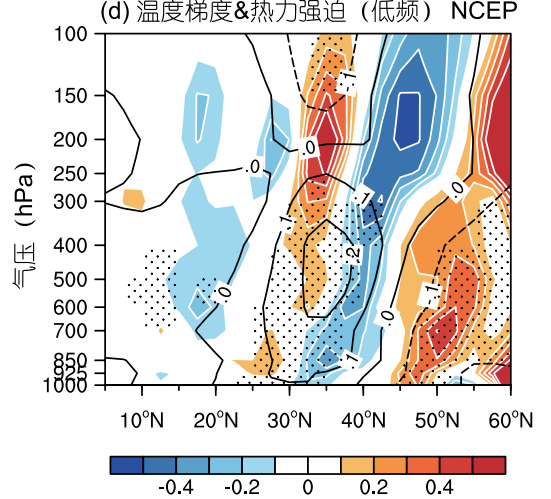

(b) 温度梯度＆热力强迫 (高频) NCEP

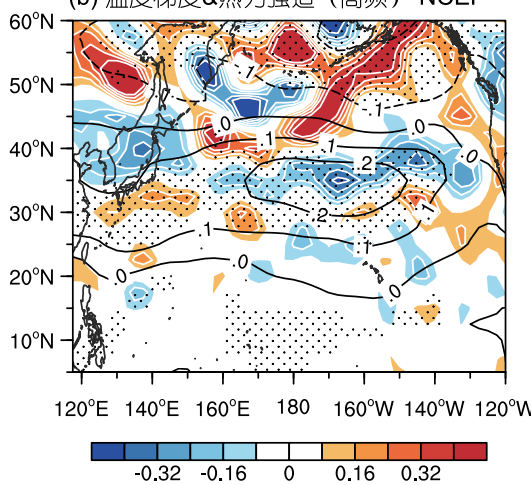

(e) 温度梯度\&热力强迫（高频） NCEP

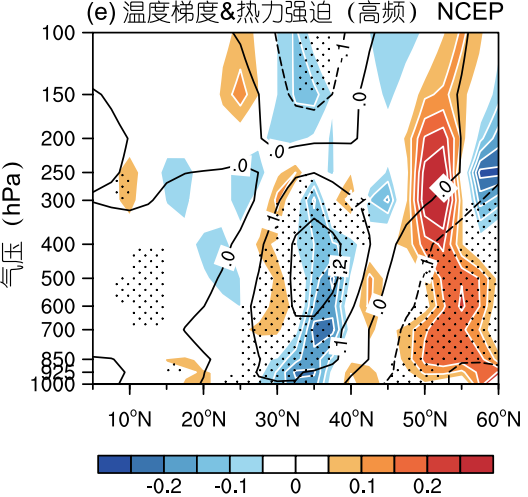

(c) 温度梯度 \&热力强迫 (高频) WRF

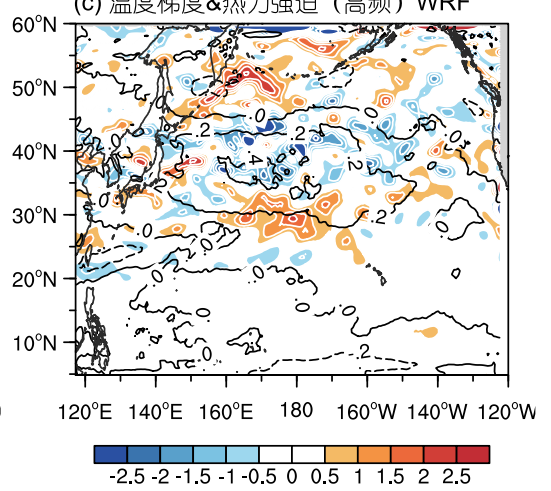

(f) 温度梯度\&热力强迫 (高频) WRF

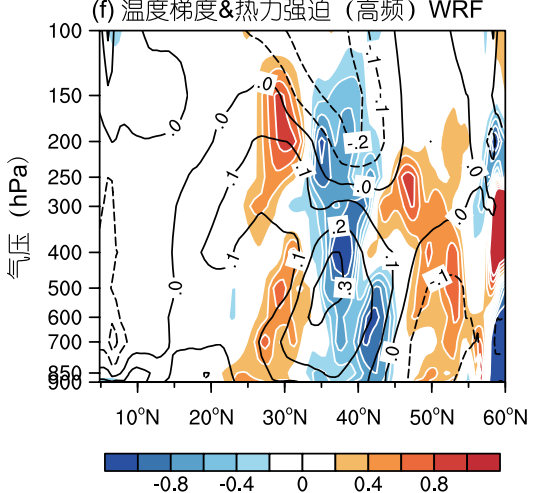

图 9 大气经向温度梯度和扰动热力强迫在副热带锋偏强年、偏弱年合成的差

等值线为大气经向温度梯度, 单位: $10^{-5} \mathrm{~K} \mathrm{~m}^{-1}$ 、填色为扰动热力强迫, 单位: $10^{-11} \mathrm{~K}(\mathrm{~m} \mathrm{~s})^{-1}$, 纬度-经度分布图为 $600 \mathrm{hPa}$ 
热带海洋锋变化下, 中纬度大气扰动异常引起纬向急 流和大气斜压性都在气候态的极大值中心再次增强的 可能机制. 而在此基础上利用不同的敏感性试验, 将 可进一步探讨副热带锋强度异常对大气的直接影响.

\section{4 讨论和结论}

本文利用海温再分析资料定义了表征冬季北太平 洋副热带海洋锋强度的指数, 并挑选出副热带海洋锋 偏强和偏弱的年份, 利用合成分析给出了观测中伴随 冬季北太平洋副热带海洋锋强度变化的中纬度大气场 异常, 特别是大气高、低频扰动活动异常及其对平均 场反馈的差别. 随后采用 NCEP/FNL数据下的副热带 海洋锋偏强、偏弱年的冬季海温场和大气边界场强迫 WRF区域大气模式, 在北太平洋上空重现了与观测一 致的大气平均场和扰动活动场异常分布. 观测和模拟 研究结果均表明, 伴随北太平洋副热带海洋锋的强度 变化, 大气平均流场以及大气扰动活动均有显著异常. 当副热带海洋锋偏强时, 对应着中纬度 $\left(30^{\circ} \mathrm{N} \sim 40^{\circ} \mathrm{N}\right)$ 北 太平洋地区的大气经向温度梯度的增强, 中纬度大气 斜压不稳定度增强, 大气高频扰动动能显著增强, 但 低频扰动动能减弱. 高、低频扰动各自的动能变化与 大气斜压性变化的关系并不一致.
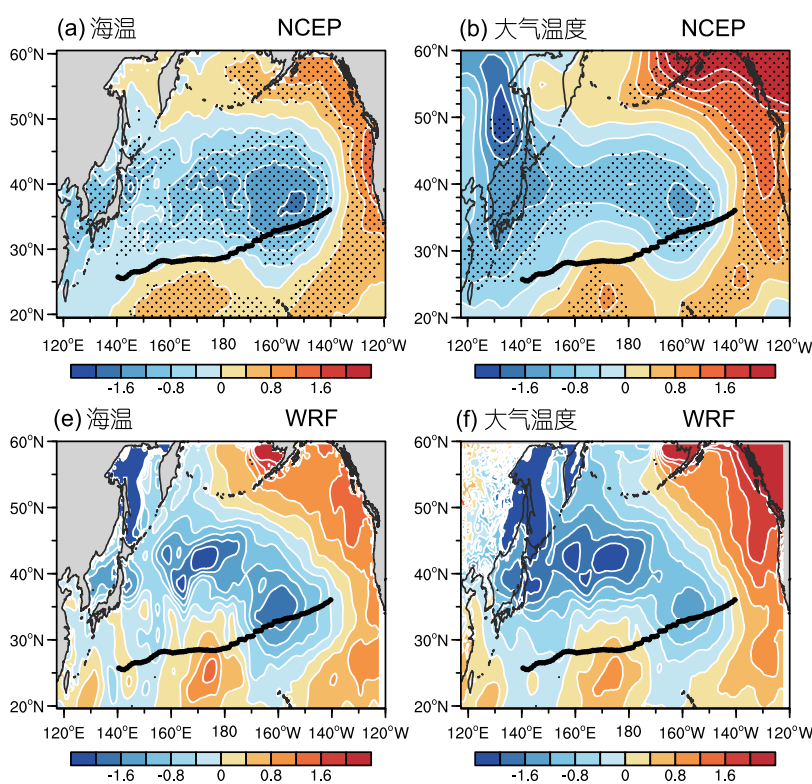

中纬度大气扰动活动通过其动力、热力强迫作 用, 影响对流层大气季节平均态分布. 当副热带海洋 锋增强时, 中纬度大气高(低)频扰动活动增强(减弱), 其动力强迫和热力强迫异常分别对大气平均风场和 温度场有显著影响, 且高、低频扰动的贡献差别显著. 其中, 动力强迫方面表现为: 伴随副热带海洋锋增强, 低频扰动对平均纬向风倾向的强迫作用减弱, 不利于 急流的纬向均匀化; 而高频扰动动力强迫增强, 有利 于急流中心北侧及下游区域西风的加速, 最终形成急 流中心偏北、偏东且增强的异常分布特征. 在热力强 迫方面: 伴随副热带海洋锋增强, 低频扰动削弱对流 层中高层大气经向温度梯度的作用偏弱, 有利于中纬 度经向温度梯度的维持; 而高频扰动的热力强迫异常 进一步减弱了中纬度大气温度经向梯度, 从而削弱中 纬度大气的斜压性.

在中纬度地区, 海洋热力状况除了通过影响大气 浴旋反馈影响季节平均大气, 海洋对大气的直接非绝 热加热也起重要作用. 海气间的感热、潜热通量主要 由海气间的温度(湿度)差和表面风速的大小决定. 当 副热带海洋锋强度变化时, 伴随着大气温度场和风场 的变化, 对应的海表热通量也有显著异常(图10). 当副 热带海洋锋偏强时, 对应着表面大气温度在北太平洋
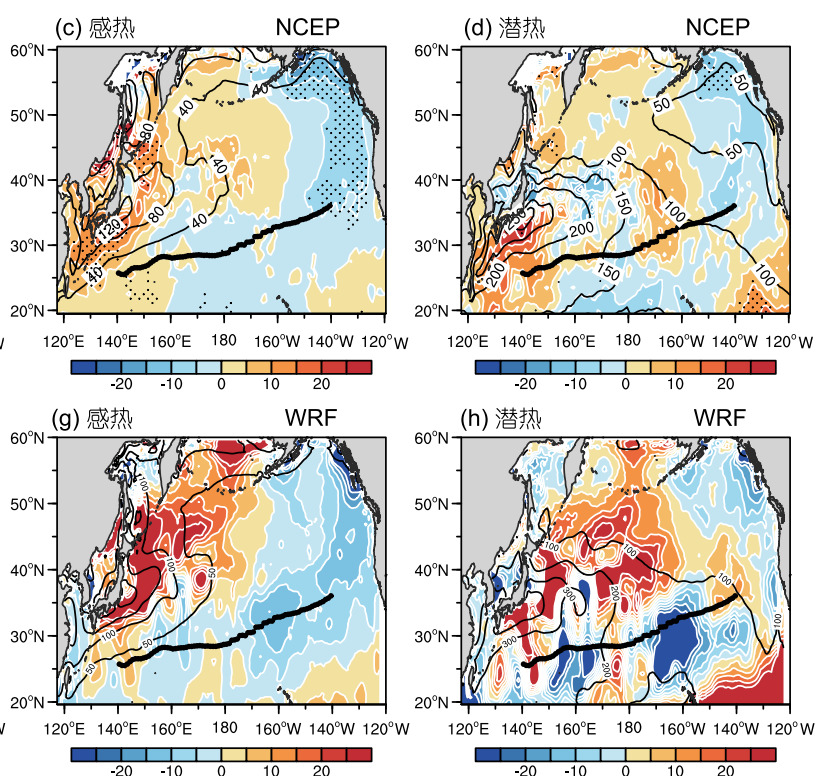

图 10 变量在副热带海洋锋偏强年、偏弱年合成的差

(a) 观测海表面温度(单位: K), (b) $1000 \mathrm{hPa}$ 大气温度(单位: $\mathrm{K}$ ), (c) 感热通量(单位: $\mathrm{W} \mathrm{m}^{-2}$ ), (d) 潜热通量(单位: $\mathrm{W} \mathrm{m}^{-2}$ ). 等值线表示热通量的 平均态, 向上为正. (e) NCEP/FNL数据的海表面温度, 即控制试验下界面强迫场. (f) (h) 同(b) (d), 只是为控制试验的结果. 黑色粗实线表 示副热带海洋锋的平均态位置. 阴影为通过 $t$ 检验的区域

1670 
$\left(30^{\circ} \mathrm{N} \sim 50^{\circ} \mathrm{N}\right)$ 上空大范围的显著负异常 (图 10b) 以及中 纬度 $\left(20^{\circ} \mathrm{N} \sim 50^{\circ} \mathrm{N}\right)$ 表面西风风速的增强(图8d), 感热、 潜热通量在西北太平洋地区显著增强(图 10c、10d), 有利于海洋向大气的热量输送, 造成中纬度 $30^{\circ} \mathrm{N}$ 以北 的海表面温度的降低(图10a). 海温在 $30^{\circ} \mathrm{N}$ 以北(南)的 负(正)异常分布有利于维持北太平洋副热带海洋锋的 强度.

在中纬度, 海气交换热通量(感热、潜热)和大气 中纬度扰动的热量输送, 均会对大气温度分布产生影 响, 进而影响大气经向温度梯度分布. 图11给出纬向 平均的大气经向温度梯度、感热通量经向梯度、潜热 通量经向梯度、以及大气高、低频扰动对温度梯度倾 向的直接热力强迫的冬季平均态及其在副热带海洋锋 偏强、偏弱年合成的分布. 在平均态下, 感热、潜热 作用(图 $11 \mathrm{~b} 、 11 \mathrm{c}$ ) 减弱中纬度 $35^{\circ} \mathrm{N}$ 以南的大气温度梯 度, 而增强 $35^{\circ} \mathrm{N}$ 以北经向温度梯度. 大气高、低频扰 动的热力强迫作用 (图 $11 \mathrm{~d} 、 11 \mathrm{e}$ ) 对中纬度 $\left(30^{\circ} \mathrm{N} 40^{\circ} \mathrm{N}\right.$ ) 大气温度经向梯度均为负贡献, 削弱中纬度大气温度 梯度. 当副热带海洋锋偏强时, 大气经向温度梯度增 强, 感热、潜热通量经向梯度(图11b、11c) 以及高频 扰动热力强迫(图11d)在中纬度均为负异常, 即这三者 的异常均减弱中纬度大气经向温度梯度, 只有低频扰 动热力强迫(图11e)在中纬度为正异常, 有利于中纬度 大气温度梯度的维持.
本文中所采用的区域大气数值模拟, 首先是利用 与观测中强弱年一致的海温和大气边界强迫区域大 气模式进行实景模拟(控制试验), 在北太平洋上空重 现了与观测中一致的大气浴旋活动异常、西风急流 异常以及大气经向温度梯度场异常分布. 然而, 实景 模拟(控制试验)的结果包含了副热带海洋锋强度的变 化以及大气侧边界条件的变化对北太平洋上空大气 的可能影响. 因此, 本文另进行了两组敏感性试验, 分 别利用副热带海洋锋强(弱)年的大气侧边界条件配合 副热带海洋锋弱(强)年的海温场下边界条件进行模拟 (具体试验设计如表1所示). 通过强年控制试验与强 年边界弱年海温敏感性试验的差值(图12a 12d), 以及 弱年边界强年海温敏感性试验与弱年控制试验的差 值(图12e 12f), 得到在不同的大气侧边界条件下, 副 热带海洋锋的强度变化对大气环流场影响的异同. 如 图12e所示, 在副热带海洋强(弱)年的大气侧边界条件 下, 副热带海洋锋强度增强的海温场强迫, 导致与观 测和控制试验结果相似的中纬度大气扰动异常(高频 大气扰动活动增强, 低频大气扰动减弱, 图12c、12d、

$12 \mathrm{~g} 、 12 \mathrm{~h})$. 而高、低频扰动活动, 通过各自的扰动动 力强迫和热力强迫异常, 最终形成纬向急流和中纬度 大气斜压性都在气候态的极大值中心再次增强的结 果(图12a、12b、12e、12f), 但异常强度弱于控制试 验. 敏感性试验的结果表明, 冬季北太平洋副热带海
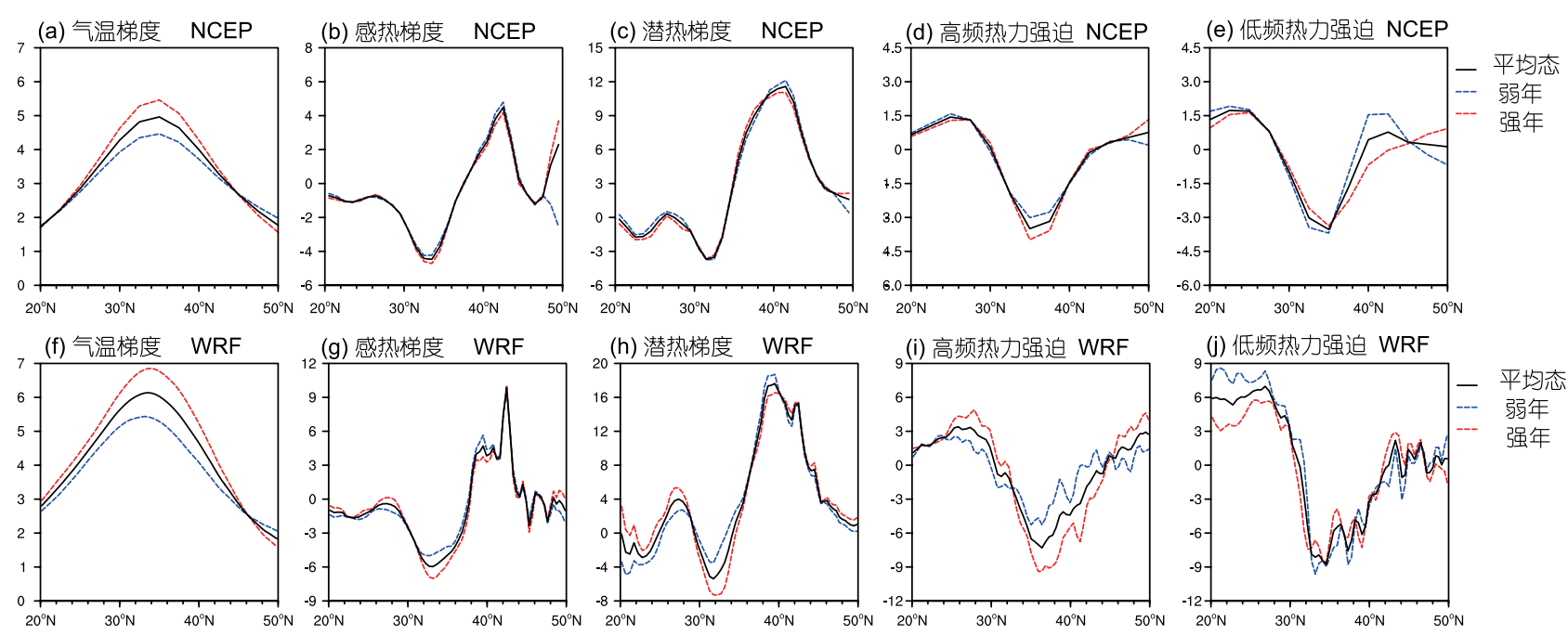

图 $111^{2} 140^{\circ} \mathrm{E} 140^{\circ} \mathrm{W}$ 纬向平均的大气变量冬季平均态及其在副热带锋偏强年、偏弱年的合成

(a) 观测大气经向温度梯度 $\left(850 \sim 250 \mathrm{hPa}\right.$ 垂直积分, 单位: $\left.10^{-5} \mathrm{~K} \mathrm{~m}^{-1}\right)$, (b) 海表面感热通量的经向梯度 (单位: $\left.10^{-5} \mathrm{~W} \mathrm{~m} \mathrm{~m}^{-3}\right)$, (c) 海表面潜热通量 的经向梯度 (单位: $\left.10^{-5} \mathrm{~W} \mathrm{~m}^{-3}\right)$, (d) 观测大气高频扰动的热力强迫 $\left(850 \sim 250 \mathrm{hPa}\right.$ 垂直积分, 单位: $\left.10^{-11} \mathrm{~K}(\mathrm{~m} \mathrm{~s})^{-1}\right)$, (e) 观测大气低频扰动的热力 强迫 $\left(850 \sim 250 \mathrm{hPa}\right.$ 垂直积分, 单位: $\left.10^{-11} \mathrm{~K}(\mathrm{~m} \mathrm{~s})^{-1}\right)$. (f) (j) 同(a) (e), 只是为控制试验的结果 



图 $12140^{\circ} \mathrm{E} \sim 140^{\circ} \mathrm{W}$ 纬向平均的大气变量在副热带锋强、弱态下的差

(a) 纬向平均大气经向温度梯度(单位: $10^{-5} \mathrm{~K} \mathrm{~m}^{-1}$ ), (b) 纬向风速 (单位: $\mathrm{m} \mathrm{s}^{-1}$ ), (c) 大气高频扰动动能 (单位: $\mathrm{m}^{2} \mathrm{~s}^{-2}$ ), (d) 大气低频扰动动能(单 位: $\mathrm{m}^{2} \mathrm{~s}^{-2}$ ). 等值线为控制实验的差异, 填色为强年控制试验与强年边界弱年海温敏感性试验中的差异. (e) (h)同(a) (d), 只是填色为弱年边 界强年海温敏感性试验与弱年控制实验的差异

洋锋的强度变化可以引起如实际观测(或实景模拟)所 示的大气扰动活动以及大气环流的变化, 并验证观测 中发现的高、低频扰动影响平均场的可能机制. 但敏 感性试验中的大气异常较弱, 且在不同的大气侧边界 下, 相同的海温强迫得到的中纬度大气扰动异常虽然 整体表现较为接近, 但在北纬 $45^{\circ} \mathrm{N}$ 以北(图 $12 \mathrm{~d} 、 12 \mathrm{~h}$ ) 还存在一定的差别. 说明在模式中, 除了下垫面海洋 锋的影响, 大气侧边界的变化对大气环流异常也有作 用. 大气侧边界的变化包括边界输入的扰动和边界进 入的平均背景场的异常, 它们对该区域内的大气扰动 活动以及大气环流场都有影响. 只是在目前的试验中, 还不能具体分析其各自的相对贡献. 目前的试验设计 也未排除伴随副热带海洋锋强弱变化下北太平洋其 他海区的海温差异影响 (虽然NCEP/FNL资料下其它 海域内海温梯度变化很小). 此外, 这种伴随副热带海 洋锋强度变化的北太平洋上空大气环流异常和大气 浴旋扰动异常, 如何反作用于北太平洋海温场, 能否 构成某种副热带海域海温异常与中纬度大气西风急 流之间的反馈机制等科学问题, 都有待后续的工作继 续研究.

致谢感谢三位审稿专家的建议和意见. 感谢江苏省 气候变化协同创新中心的资助.

\section{参考文献}

管秉贤. 1987. 副热带逆流二十年研究概况. 海洋科学进展, 6: 71-86

任雪娟, 杨修群, 韩博. 2007. 北太平洋冬季海-气耦合的主模态及 其与瞬变扰动异常的联系. 气象学报, 65: 52-62

徐海明, 王琳玮, 何金海. 2008. 卫星资料揭示的春季黑潮海区海 洋对大气的影响及其机制研究. 科学通报, 53: 463-470

徐蜜蜜, 徐海明, 朱素行. 2010. 春季我国东部海洋温度锋区对大 气的强迫作用及其机制研究. 大气科学, 34: 1071-1087

谢傲, 徐海明, 徐蜜蜜, 马静. 2014. 海表面盛行风背景下大气对黑 潮海洋锋的响应特征. 气象科学, 34: 355-364

朱伟军, 孙照渤. 1999. 冬季太平洋SST异常对风暴轴和急流的影 响. 南京气象学院学报, 22: 575-581

Chen F, Dudhia J. 2001. Coupling an advanced land surface-hydrology model with the Penn State-NCAR MM5 modeling system. Part I: Model implementation and sensitivity. Mon Weather Rev, 129: 569-585

Dudhia J. 1989. Numerical study of convection observed during the winter monsoon experiment using a mesoscale two-dimensional model. J Atmos Sci, 46: 3077-3107

Hayes S P, Mcphaden M J, Wallace J M. 1989. The influence of Sea-Surface Temperature on surface wind in the Eastern Equatorial Pacific: Weekly to monthly variability. J Clim, 2: 1500-1506

Hong S Y, Noh Y, Dudhia J. 2006. A new vertical diffusion package with an explicit treatment of entrainment processes. Mon Wea Rev, 134: $2318-2341$

Hoskins B J, Hodges K I. 2002. New perspectives on the northern hemi- 
sphere winter storm tracks. J Atmos Sci, 59: 1041-1061

Hoskins B J, James I N, White G H. 1983. The shape, propagation and mean-flow interaction of large-scale weather systems. J Atmos Sci, 40: $1595-1612$

Hoskins B J, Valdes P J. 1990. On the existence of storm-tracks. J Atmos Sci, 47: 1854-1864

Hotta D, Nakamura H. 2011. On the significance of the sensible heat supply from the ocean in the maintenance of the mean baroclinicity along storm tracks. J Clim, 24: 3377-3401

Hsiung J. 1985. Estimates of global oceanic meridional heat transport. J Phys Oceanogr, 15: 1405-1413

Janjić Z I. 1994. The step-mountain eta coordinate model: Further developments of the convection, viscous sublayer, and turbulence closure schemes. Mon Wea Rev, 122: 927-945

Janjić Z I. 2000. Comments on "development and evaluation of a convection scheme for use in climate models". J Atmos Sci, 57: 3686-3686

Kalnay E, Kanamitsu M, Kistler R, Collins W, Deaven D, Gandin L, Iredell M, Saha S, White G, Woollen J, Zhu Y, Leetmaa A, Reynolds R, Chelliah M, Ebisuzaki W, Higgins W, Janowiak J, Mo K C, Ropelewski C, Wang J, Jenne R, Joseph D. 1996. The NCEP/NCAR 40-Year Reanalysis Project. Bull Amer Meteor Soc, 77: 437-471

Kelly K A, Small R J, Samelson R M, Qiu B, Joyce T M, Kwon Y O, Cronin M F. 2010. Western boundary currents and frontal airsea interaction: Gulf stream and Kuroshio Extension. J Clim, 23: 5644-5667

Kobashi F, Xie S P, Iwasaka N, Sakamoto T T. 2008. Deep atmospheric response to the North Pacific Oceanic subtropical front in spring. $\mathrm{J}$ Clim, 21: 5960-5975

Kwon Y O, Alexander M A, Bond N A, et al. 2010. Role of the gulf stream and Kuroshio-Oyashio systems in large-scale atmosphere-ocean interaction: A review. J Clim, 23: 3249-3281

Lindzen R S, Farrell B. 1980. A simple approximate result for the maximum growth rate of baroclinic instabilities. J Atmos Sci, 37: 1648-1654

Lindzen R S, Nigam S. 1987. On the role of sea surface temperature gradients in forcing low-level winds and convergence in the tropics. J Atmos Sci, 44: 2418-2436

Minobe S, Kuwano-yoshida A, Komori N, Xie S P, Small R J. 2008. Influence of the gulf stream on the troposphere. Nature, 452: 206-209

Mlawer E J, Taubman S J, Brown P D, Iacono M J, Clough S A. 1997. Radiative transfer for inhomogeneous atmospheres: RRTM, a validated correlated-k model for the longwave. J Geophys Res, 102: 16663-16682

Nakamura H, Lin G, Yamagata T. 1997. Decadal climate variability in the north pacific during the recent decades. Bull Amer Meteor Soc, 78: 2215-2225

Nakamura H, Kazmin A S. 2003. Decadal changes in the North Pacific oceanic frontal zones as revealed in ship and satellite observations. $\mathrm{J}$ Geophys Res, 108: 3078
Nakamura H, Sampe T, Tanimoto Y, Shimpo A. 2004. Observed associations among storm tracks, jet streams and midlatitude oceanic fronts. Geophys Monogr, 147: 329-345

Nakamura H, Shimpo A. 2004. Seasonal variations in the southern hemisphere storm tracks and jet streams as revealed in a reanalysis dataset. J Clim, 17: 1828-1844

Nakamura H, Sampe T, Goto A, Ohfuchi W, Xie S P. 2008. On the importance of midlatitude oceanic frontal zones for the mean state and dominant variability in the tropospheric circulation. Geophys Res Lett, 35: 971-978

Nakamura M, Yamane S. 2009. Dominant anomaly patterns in the nearsurface baroclinicity and accompanying anomalies in the atmosphere and oceans. Part I: North Atlantic basin. J Clim, 22: 880-904

Nakamura M, Yamane S. 2010. Dominant anomaly patterns in the nearsurface baroclinicity and accompanying anomalies in the atmosphere and oceans. Part II: North Pacific basin. J Clim, 23: 6445-6467

Nie Y, Zhang Y, Yang X Q, Chen G. 2013. Baroclinic anomalies associated with the southern hemisphere annular mode: Roles of synoptic and low-frequency eddies. Geophys Res Lett, 40: 2361-2366

Nonaka M, Nakamura H, Taguchi B, Komori N, Kuwano-yoshida A, Takaya K. 2009. Air-sea heat exchanges characteristic of a prominent midlatitude oceanic front in the south indian ocean as simulated in a high-resolution coupled GCM. J Clim, 22: 6515-6535

Nonaka M, Nakamura H, Tanimoto Y, Kagimoto T, Sasaki H. 2008. Interannual-to-decadal variability in the oyashio and its influence on temperature in the subarctic frontal zone: An eddy-resolving OGCM simulation. J Clim, 21: 6283-6303

Peixoto J P, Oort A H. 1992. Physics of Climate. American Institute of Physics. 520

Rayner N A, Parker D E, Horton E B, Folland C K, Alexander L V, Rowell D P. 2003. Global analyses of SST sea ice and night marine air temperature since the late nineteenth century. J Geoghys Res, 108: 1063-1082

Reynolds R W, Smith T M, Liu C, Chelton D B, Casey K S, Schlax M G. 2007. Daily high-resolution-blended analyses for sea surface temperature. J Clim, 20: 5473-5496

Roden G I. 1975. On North Pacific temperature, salinity, sound velocity and density frontsand their relation to the wind and energy flux fields. J Phys Oceanogr, 5: 557-571

Roden G I. 1980. On the variability of surface temperature fronts in the western Pacific, as detected by satellite. J Geophys Res, 85: 2704

Sampe T, Nakamura H, Goto A, Ohfuchi W. 2010. Significance of a midlatitude SST frontal zone in the formation of a storm track and an eddy-driven westerly jet. J Clim, 23: 1793-1814

Skamarock W C, Klemp J B, Dudhia J, Gill D O, Barker D M, Wang W, Powers J G. 2005. A description of the advanced research WRF version 2. National Center For Atmospheric Research Boulder Co Mesoscale and Microscale Meteorology Div

Small R J, Deszoeke S P, Xie S P, O'neill L, Seo H, Song Q, Cornillon P, 
Spall M, Minobe S. 2008. Air-sea interaction over ocean fronts and eddies. Dyn Atmos Ocean, 45: 274-319

Taguchi B, Nakamura H, Nonaka M, Komori N, Kuwano-yoshida A, Takaya K, Goto A. 2012. Seasonal evolutions of atmospheric response to decadal SST anomalies in the North Pacific subarctic frontal zone: Observations and a coupled model simulation. J Clim, 25: 111-139

Taguchi B, Nakamura H, Nonaka M, Xie S P. 2009. Influences of the Kuroshio/Oyashio Extensions on air-sea heat exchanges and stormtrack activity as revealed in regional atmospheric model simulations for the 2003/04 cold season. J Clim, 22: 6536-6560

Tanimoto Y, Kanenari T, Tokinaga H, Xie S P. 2011. Sea level pressure minimum along the Kuroshio and its extension. J Clim, 24: 4419-4434

Thompson G, Rasmussen R M, Manning K. 2004. Explicit forecasts of winter precipitation using an improved bulk microphysics scheme. Part I: Description and sensitivity analysis. Mon Weather Rev, 132: 519-542

Tokinaga H, Tanimoto Y, Xie S P, Sampe T, Tomita H, Ichikawa H. 2009. Ocean frontal effects on the vertical development of clouds over the Western North Pacific: In situ and satellite observations. J Clim, 22: $4241-4260$
Uda M, Hasunuma K. 1969. The eastward subtropical countercurrent in the western North Pacific Ocean. J Oceanogr Soc Japan, 25: 201-210

Wallace J M, Mitchell T P, Deser C. 1989. The influence of sea-surface temperature on surface wind in the Eastern Equatorial Pacific: Seasonal and interannual variability. J Clim, 2: 1492-1499

Xie S P. 2004. Satellite observations of cool ocean-atmosphere interaction. Bull Amer Meteor Soc, 85: 195-208

$\mathrm{Xu}$ H, Tokinaga H, Xie S P. 2010. Atmospheric effects of the Kuroshio large meander during 2004-05. J Clim, 23: 4704-4715

$\mathrm{Xu}$ H, Xu M, Xie S P, Wang Y. 2011. Deep atmospheric response to the spring Kuroshio over the East China Sea. J Clim, 24: 4959-4972

Yasuda I. 2003. Hydrographic structure and variability in the KuroshioOyashio transition area. J Oceanography, 59: 389-402

Yu L, Jin X, Weller R A. 2008. Multidecade Global Flux Datasets from the Objectively Analyzed Air-sea Fluxes (OAFlux) Project: Latent and sensible heat fluxes, ocean evaporation, and related surface meteorological variables. OAFlux Project Technical Report. OA-2008-01, 64

Yuan X, Talley L D. 1996. The subarctic frontal zone in the North Pacific: Characteristics of frontal structure from climatological data and synoptic surveys. J Geophys Res, 101: 16491-16508 